\title{
A study of impacts of tropospheric synoptic processes on the genesis and evolution of extreme total ozone anomalies over southern South
} America

\author{
Pablo O. Canziani, ${ }^{1}$ Rosa H. Compagnucci, and Susana A. Bischoff \\ Departamento de Ciencias de la Atmósfera y los Océanos, Facultad de Ciencias Exactas y Naturales, Universidad de Buenos \\ Aires/CONICET, Buenos Aires, Argentina \\ Walter E. Legnani ${ }^{1}$ \\ Instituto de Cálculo, Facultad de Ciencias Exactas y Naturales, Universidad de Buenos Aires, Buenos Aires, Argentina \\ Received 19 June 2001; revised 27 February 2002; accepted 1 March 2002; published 18 December 2002.
}

[1] During the austral autumn of 1997, a sequence of record low ozone events with anomalous behavior occurred at subtropical latitudes to midlatitudes over southern South America, also known as the South Cone (Chile, Argentina, Uruguay, and Southern Brazil). The extreme low ozone events took place in May and early June 1997, i.e., at a time of the year when according to the climatological studies for Northern Hemisphere ozone miniholes, the most significant events would not be expected (if such studies could be simply extrapolated to the Southern Hemisphere). The first and most prominent ozone minihole, with a quasistationary evolution, reached values near 200 DU, i.e., a negative anomaly near 90 DU, close to $40^{\circ} \mathrm{S}$. Simultaneously, extreme weather conditions were observed over the South Cone: three significant blocking events took place separated by short intervals. Both the behavior of the ozone layer over the region and the evolution of the blocking events were analyzed. As expected, the evolution of the total ozone column is shown to be linked to these perturbed weather conditions. Despite the apparently similar nature of the blocking events and of the ozone decrease during each of these events, the present study shows that the response of the UT/LS region is different in each case. The respective roles of the vertical displacement of the tropopause and the horizontal advection/divergence of ozone is discussed for the two most important events, showing how these two mechanisms combine in different ways to yield very low total ozone values. The vertical displacement of the tropopause, coupled to the size of the tropopause pressure gradient, appears to be the most efficient mechanism to modify the total ozone column amounts. INDEX TERMS: 3364 Meteorology and Atmospheric Dynamics: Synoptic-scale meteorology; 0341 Atmospheric Composition and Structure: Middle atmosphere-constituent transport and chemistry (3334); 3362 Meteorology and Atmospheric Dynamics: Stratosphere/troposphere interactions; 3384 Meteorology and Atmospheric Dynamics: Waves and tides; KEYWORDS: ozone, tropospherestratosphere coupling, miniholes, blocking events

Citation: Canziani, P. O., R. H. Compagnucci, S. A. Bischoff, and W. E. Legnani, A study of impacts of tropospheric synoptic processes on the genesis and evolution of extreme total ozone anomalies over southern South America, J. Geophys. Res., 107(D24), 4741, doi:10.1029/2001JD000965, 2002.

\section{Introduction}

[2] The occurrence of so-called ozone "miniholes" and low ozone events over inhabited areas, has become, in recent years, a source of public concern in temperate Southern Hemisphere countries, already worried by the possible consequences of the Antarctic Ozone "hole." The possibility that active ozone depleting processes,

\footnotetext{
${ }^{1}$ Also at Unidad Docente Ciencias Básicas Matemática, Facultad Regional Buenos Aires, Universidad Tecnológica Nacional, Buenos Aires, Argentina.

Copyright 2002 by the American Geophysical Union. 0148-0227/02/2001JD000965
}

thought to be limited to the so-called Antarctic ozone "hole" in late winter and spring, could be extending to southern midlatitudes, has been a constant source of concern. This has been particularly so in recent years, when low ozone episodes and prominent ozone minihole events occurred over inhabited areas. Furthermore the local weather services are now regularly providing UV radiation levels and alerts, with mixed responses from the population. During the last few years the most significant low ozone event over heavily populated continental areas of the hemisphere took place in May 1997, over Chile, Argentina, and Uruguay, also referred to as the Southern Cone countries.

[3] By now, it is well established that ozone depletion at high latitudes, within the polar vortices, is basically due to the 
heterogeneous, catalytic destruction of stratospheric ozone by anthropogenic chlorine and bromine, under the extreme atmospheric conditions present there [Solomon, 1999, and references therein]. On the other hand, the main mechanisms resulting in ozone change and/or redistribution and extreme variability outside polar regions, other than the ozone depleting homogeneous gas phase processes in the mid to upper stratosphere, are of another nature, i.e., mainly dynamical [e.g., Salby and Callaghan, 1993, and references therein]. Furthermore the significance of ozone depleting heterogeneous processes outside polar regions, particularly on lower stratosphere aerosols, is still under scrutiny [Solomon, 1999].

[4] Many of the day-to-day modifications in total ozone content can be linked to perturbations in the atmospheric circulation. Dobson et al. [1929] were the first to point out that total column ozone levels could undergo substantial, local short-term variability which correlates closely with synoptic weather systems. Dobson [1973] reviewed this issue, clearly establishing links between short-term ozone changes and weather. More recently, Vaughan and Price [1991] established links between vorticity in the lower stratosphere and total ozone. In particular such relationships were found for reversible deformations to the flow in synoptic and subsynoptic scales, which depend on the amplitude and depth of the vorticity anomaly. Salby and Callaghan [1993] described the role of vertical motion of isentropic surfaces in the lower stratosphere on the total ozone variability. They further pointed out that the horizontal component of the columnaveraged motion in the lower stratosphere introduces total ozone anomalies by rearranging the column-averaged ozonemixing ratio, in other words horizontal advection in the lower stratosphere can contribute significantly. Steinbrecht et al. [1998] carried out an extensive analysis of the relationship between tropopause height and ozone over Hohenpeissenberg in Germany. Vaughan and Timmis [1998] studied a lower stratospheric low ozone layer found over Europe in January 1992 that had originated at subtropical latitudes. The ozone profile in the layer had a structure similar to that observed in the equatorward flank of the subtropical jet, confirming the contribution of horizontal transport on midlatitude low ozone events. Hood et al. [1999] studied the trends in the Northern Hemisphere zonal wind, total ozone and Rossby wave breaking. They concluded that there has been an enhancement in the occurrence of anticyclonic, poleward Rossby wave breaking events that transport low potential vorticity, ozone-poor air, from the subtropical troposphere to the midlatitude lower stratosphere. The day to day observations made at a given location or on the regional or global total column ozone maps are thus basically due to changes in the ozone distribution in the region of the ozone layer closest to the tropopause.

[5] More specifically referring to the ozone "miniholes," Mc Kenna et al. [1989] studied their formation close to and within the main Antarctic polar vortex using the AAOE data. They attributed the minihole genesis to synoptic scale, tropospherically forced reversible advection. Rood et al. [1992] and Orsolini et al. [1995] pointed out that it is the combination of both vertical and horizontal motions that give rise to the observed "miniholes." Peters and Waugh [1997] discussed the perturbations to the mean circulation in the upper troposphere and lower stratosphere that can lead to the formation of a minihole. Mc Cormack and Hood [1997] and James [1998] carried out studies referring to the frequency and climatology of ozone miniholes in the Northern Hemisphere. The first one considered the trends in the occurrence of such low ozone events in the Northern Hemisphere. The latter analyzed the geographic and annual cycle distribution of these episodes and their depth. It must be noted that these studies refer to upper mid to high northern latitudes. Only Barsby and Diab [1995] studied the relationships between total ozone and tropospheric synoptic episodes in the Southern Hemisphere, over central and southern Africa and the surrounding oceans. They were able to find significant correlations between the tropospheric events and ozone only during the cutoff lows, with very large, positive ozone anomalies. They found a negligible correlation between column ozone and anticyclonic episodes for this region of the Southern Hemisphere.

[6] Much if not most of the above effort to understand these regional processes using observational products and models has been focused on the regions close to the polar vortices and ozone holes, in particular for the Northern Hemisphere. The occurrence of such processes at southern midlatitudes has not been studied as such. This work thus focuses on a series of low ozone or "minihole" episodes with peculiar characteristics that were observed over the Southern Cone during May 1997. At the same time, during 45 days it was possible to observe 3 blocking events, separated by intervals a few days long during which the circulation returned to the more usual patterns. The sequence of miniholes/ozone minima and ozone ridges took place together with this sequence of perturbations to the basic circulation of the region.

[7] The aim of the present study is the identification and analysis of the synoptic situation during the first two minihole events, from the lower troposphere $(1000 \mathrm{hPa})$ up to the lower stratosphere, and how it affected the ozone layer. This includes the analysis of geopotential height, temperature and wind fields in this height range as well as the behavior of the tropopause. The evolution of the first very strong episode is compared to the subsequent ozone minihole events, which were not as deep. The data used are presented in section 2. The characteristics and behavior of the ozone layer during this period are described in section 3 . In section 4 the analysis of the synoptic situation in the troposphere and lower stratosphere is discussed. Section 5 presents the trajectory analysis for the two major low ozone events. Finally the links between the ozone miniholes and the synoptic situations are discussed in section 6 .

\section{Data}

[8] The first of the low ozone episodes reached extreme low values, significantly below all previous local/regional records registered for the month of May, both by the Buenos Aires Dobson station, operating since 1966, and the TOMS retrievals, which provide global coverage since 1978 . The lowest value at this Dobson station was 208 DU and the TOMS yielded similar values. The resulting perturbation to the mean field was of the order of -90 DU below the monthly mean over northern and central Patagonia. Perturbation values greater than $-30 \mathrm{DU}$ were observed in the region between 30 and $46^{\circ} \mathrm{S}, 50$ to $80^{\circ} \mathrm{W}$.

[9] Total ozone retrievals made by TOMS ADEOS column ozone data provide hemispheric coverage during the 


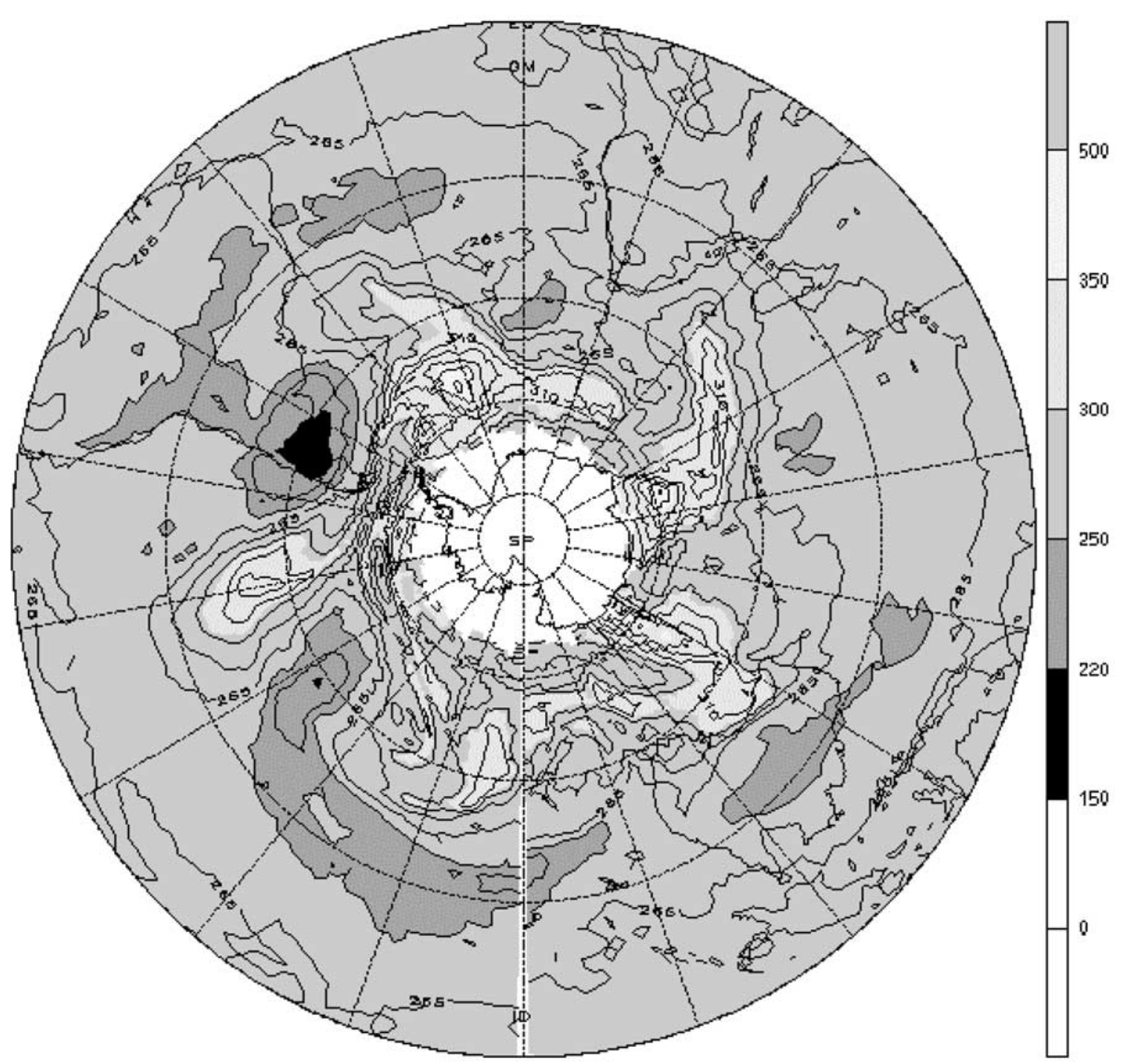

Figure 1. Total ozone field (DU) over the Southern Hemisphere on 5 May 1997 before the peak of the first ozone minimum event or minihole. Note the prominent wave 5 structure in the ozone distribution and the significant ozone decrease over southern South America.

low ozone episodes. Version 7 data is used. The reference ozone climatology, as discussed below, was established with the TOMS NIMBUS Version 7 data set. These data sets provide daily ozone retrievals with global coverage in a $1.0 \times 1.25^{\circ}$ grid. The ozone data was complemented with the Buenos Aires Dobson retrievals as well as with observations from other Dobson instruments operating in the Southern Cone region. In all cases agreement between the TOMS observations and ground-based retrievals was found to be good.

[10] In order to study the magnitude of the perturbation to the ozone field during these events a special climatology was implemented. It is necessary to consider the extent of the perturbation with respect to the average conditions prevailing at the time of its occurrence and to compare it with the climatology derived from the TOMS database. Because both the interannual variability, in particular that due to the QuasiBiennial Oscillation (QBO), and the solar cycle as well as the latitude dependent trends which could modify the signifi- cance of the minima and maxima of the process under study, it is convenient to study the perturbation as an anomaly. In consequence, an anomaly climatology was implemented so as to remove the essentially zonal mean interannual phenomena, and the zonal mean trend effects. Daily zonal mean values were calculated for all Southern latitudes sampled by the TOMS instruments during the period April-June. The daily anomalies were then calculated with respect to the corresponding zonal mean daily ozone values. Specifically, the daily and monthly anomaly climatologies were calculated for April, May, and June 1979-1992, i.e., for the TOMS NIMBUS data, and for April, May, and June 1997, for the TOMS ADEOS. All the anomaly comparisons and discussions presented here thus refer to this specific anomaly calculation and climatology.

[11] The meteorological information was obtained from the reanalysis products provided by the NCEP. Geopotential height, potential vorticity, temperature, tropopause temperature and pressure were considered both for the whole 

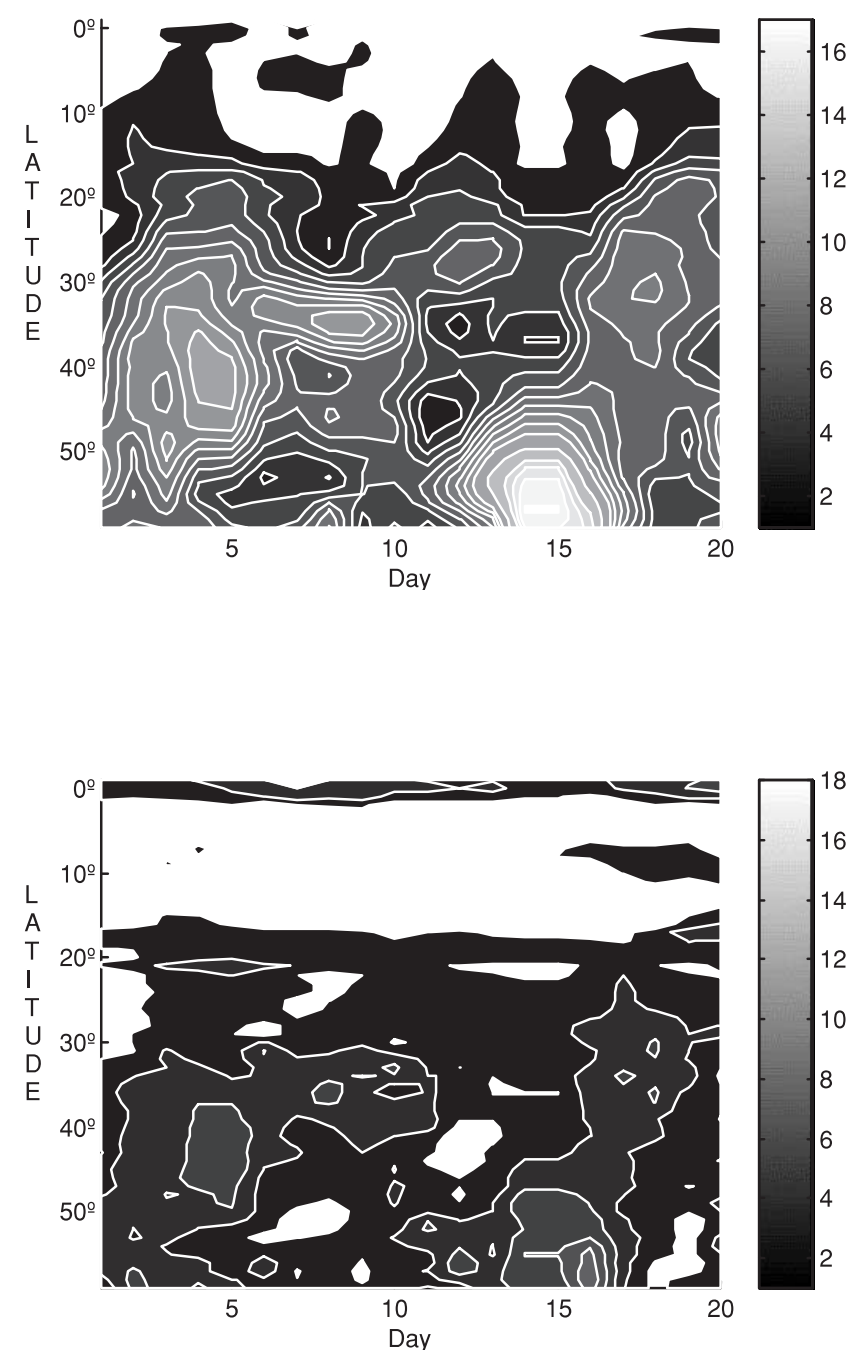

Figure 2. R.M.S. daily amplitudes zonal waves structure in total ozone for wave with zonal wave numbers 4-6 (a) and 1-3 (b) over the Southern Hemisphere.

hemisphere and the region above South America and surrounding oceans. Data corresponding to 1000, 500 and $50 \mathrm{hPa}$ were used in particular. Note that the tropopause provided by the NCEP corresponds to the thermal tropopause. Trajectories were calculated using the Goddard Automailer system, which also uses the NCEP reanalysis products.

\section{Behavior of the Southern Hemisphere Ozone Layer During May 1997}

[12] The low ozone events or miniholes that were observed over the Southern Cone countries in May 1997, that is, in the middle of the austral autumn, showed a variety of characteristics. The first and most significant one was particularly anomalous for a number of reasons:

1. It appeared at relatively low latitudes, equatorward of $46^{\circ} \mathrm{S}$.

2. The size of the low ozone region, with anomaly values deeper than -30 DU was considerable, covering a region between 30 and $46^{\circ} \mathrm{S}, 50$ to $80^{\circ} \mathrm{W}$. The deepest anomaly values in the core of the minihole reached in excess of -90 DU and total column values of the order of $205 \mathrm{DU}$ at $43^{\circ} \mathrm{S}$, $68^{\circ} \mathrm{W}$, over the Patagonian province of Chubut, Argentina.

3. It remained quasi-stationary for a comparatively extended period of time, staying over the relatively narrow longitudinal band spanned by Chile and Argentina for more than 6 days from its genesis to its disappearance over the South Atlantic.

4. It is distinctly isolated from the low ozone values in the tropics and presents no links with the high latitudes.

[13] This is a rather odd behavior since most low ozone events or miniholes appear as travelling features, poleward of $40^{\circ}$. Subsequent miniholes occurred at more usual latitudes.

[14] The hemispheric ozone distribution in late April and the first part of May 1997 had a significant, recurrent zonal wave no. 5, together with waves 4 and 6 (Figure 1). Salby [1982] and Schoeberl and Krueger [1983] pointed out that wave 5 structures are conspicuous patterns in the lower stratosphere temperature and ozone field (which behaves as a passive tracer at this height) over the Southern Hemisphere during summer. This wave has periods between 8 and 15 days and peaks close to $45^{\circ} \mathrm{S}$, near $300 \mathrm{hPa}$ [Salby, 1982]. It extends between 65 and $30^{\circ} \mathrm{S}$, up to about $30 \mathrm{hPa}$. Schoeberl and Krueger [1983] demonstrated that this wave perturbation has an impact on the total ozone field, both through vertical and horizontal advection, and that both of these processes contribute in almost the same amounts to the total ozone perturbation.

[15] A Southern Hemisphere total ozone daily spatial spectral analysis corroborates the observation that during most of May 1997 planetary waves 4 through 6 (Figure 2a) were indeed dominant with only weak contributions from waves 1-3 (Figure 2b). The r.m.s. (root mean square) timelatitude plot for waves 4-6 shows the presence of such a strong wave event during the first week approximately, in close agreement with Salby's description of wave 5 and associated waves 4 and 6 . It is interesting to note that wave 5 (not shown separately) is the dominant wave in this wave packet when they occur, though at times wave 4 can be similar or somewhat larger. Furthermore, near the middle of the month, there is a high-latitude, short-lived, very strong wave $4-6$ structure, i.e., south of $50^{\circ} \mathrm{S}$, which appears to be somewhat distinct from Salby's description. Inspection of daily column ozone maps during those days confirms the existence of such wave behavior at higher latitudes.

[16] Before proceeding further, it is useful to look at the evolution of the total ozone for the period under study (Figure 3). On 30 April and 1 May the total ozone field had a wave 4 rotating pattern initially south of $40^{\circ} \mathrm{S}$ with a few isolated maxima and minima between 40 and $25^{\circ} \mathrm{S}$. This zonal wave 4 pattern evolved and became more distinct with pronounced ridges and troughs between 20 and $40^{\circ} \mathrm{S}$. The ozone trough to the west of the continent, over the Southern Pacific at approximately $35^{\circ} \mathrm{S}$, became deeper during this process. The development of a distinct wave 5 pattern began on 2 and 3 May (Figure 3a). This wave pattern extended as far north as $20^{\circ} \mathrm{S}$, with the largest variance located close to $40-45^{\circ} \mathrm{S}$. Deep troughs with values below 220 DU, i.e., ozone holes, appeared at $38-45^{\circ} \mathrm{S}, 80^{\circ} \mathrm{W}$, close to the Southern Cone and at $38^{\circ} \mathrm{S}, 130^{\circ} \mathrm{W}$ over the Central South Pacific. 


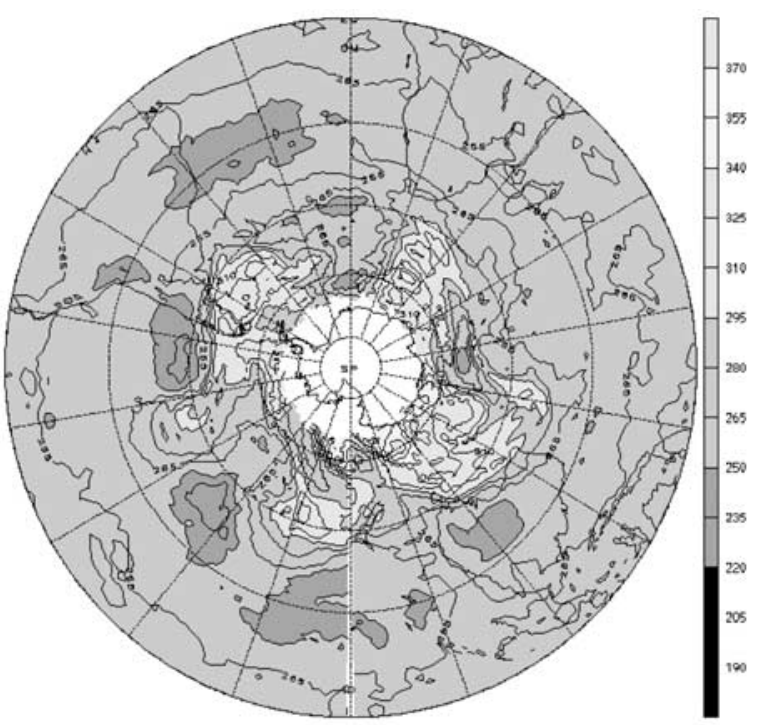

a)

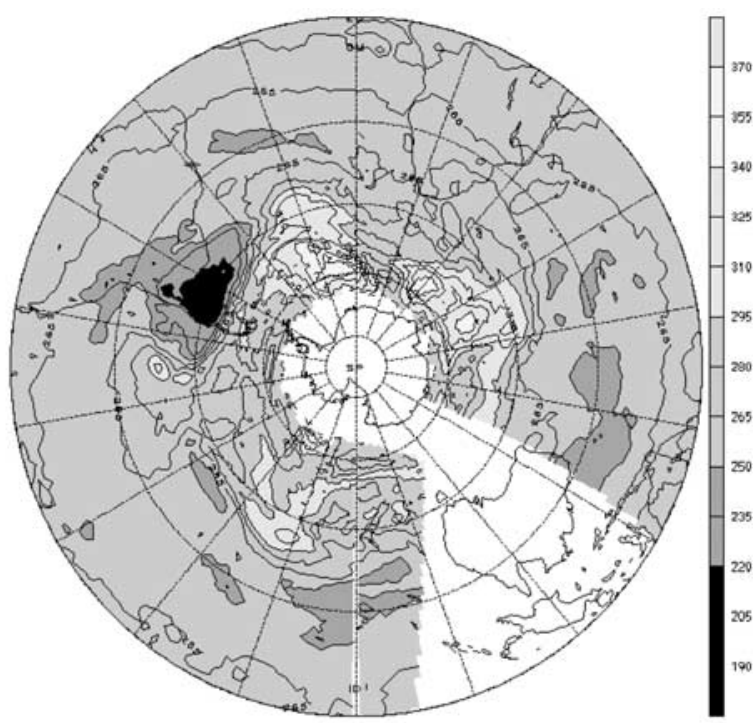

b)

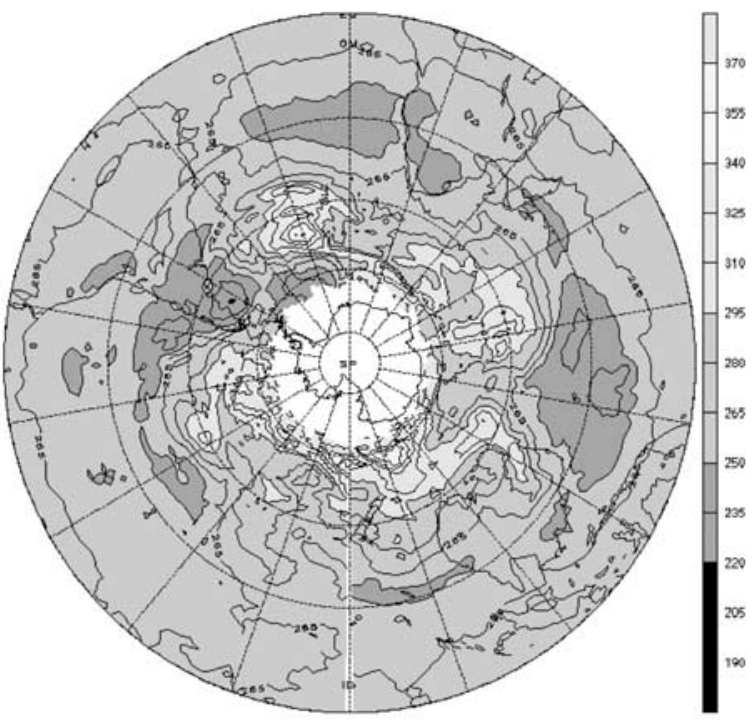

c)

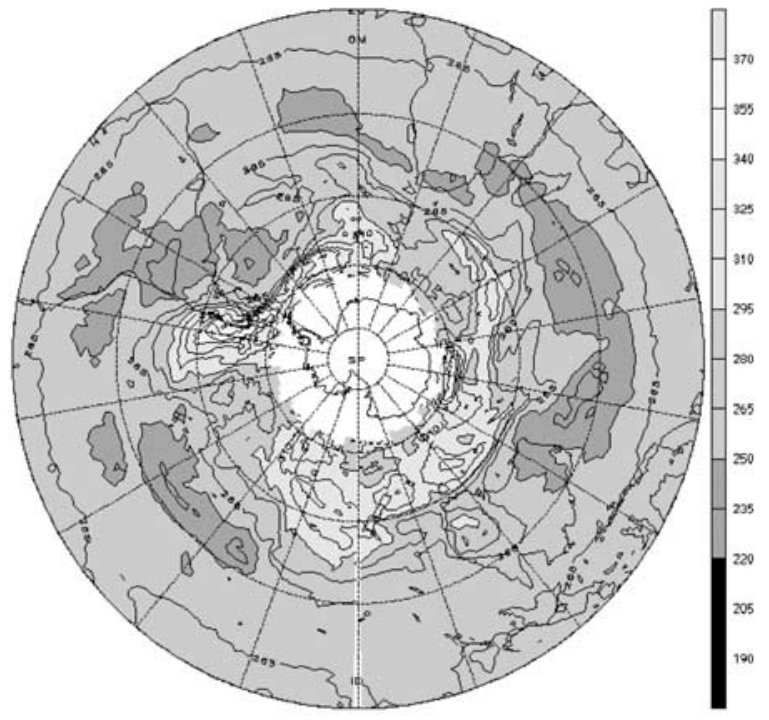

d)

Figure 3. Total ozone field evolution (in DU) over the Southern Hemisphere during May 1997: (a) 2 May, (b) 7 May, (c) 14 May, (d) 17 May, (e) 27 May, and (f) 30 May.

[17] The wave 5 pattern continued its rotation and the ozone minihole core crossed the Andes by 5 May (Figure 1), when it became stationary over the Pampas region and northern Patagonia. At the same time the ozone trough became deeper. The $220 \mathrm{DU}$ isopleth extended from 30 to $45^{\circ} \mathrm{S}$ and 70 to $45^{\circ} \mathrm{W}$ by 6 and 7 May (Figure $3 \mathrm{~b}$ ). Furthermore a very sharp ozone gradient developed on the southern edge of the minihole. At this time the $-30 \mathrm{DU}$ anomaly isopleth extended from 25 to $50^{\circ} \mathrm{S}$ and 85 to $40^{\circ} \mathrm{W}$, while the $-60 \mathrm{DU}$ anomaly isopleth included a region between 35 to $45^{\circ} \mathrm{S}$ and 80 to $45^{\circ} \mathrm{W}$. The core minimum anomaly values were close to -90 DU over northern Patagonia. The wave 5 pattern was rapidly distorted when this particular trough became stationary, after crossing the Andes. It must be noted that at this time the anomaly null isopleth had extended over Southern Peru, Bolivia and Southern Brazil on the northern edge.

[18] By 8 May (Figure 4b) the ozone minihole core became distorted, yet with only a limited recovery in the ozone levels and virtually no displacement. The recovery was of the order of 10 to $20 \mathrm{DU}$ in the core of the low ozone region. However, the -30 DU isopleth did not undergo any changes. During the subsequent days there was no apparent planetary wave structure over the Southern Hemisphere. On 10 May the minihole had virtually disappeared (Figure 4c) though the total ozone levels over the Southern Cone 


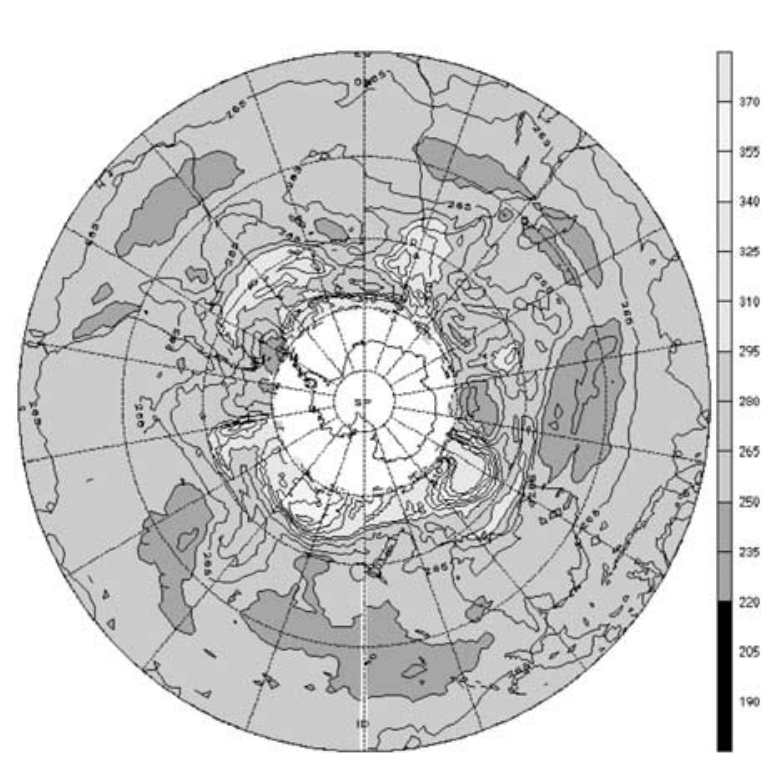

e)

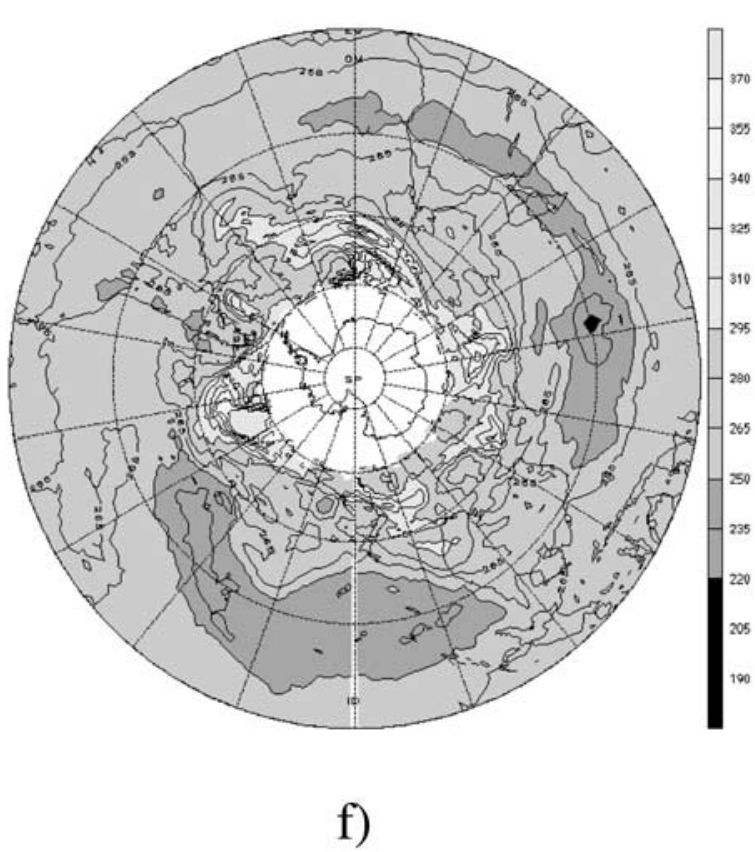

f)

Figure 3. (continued)

remained low, under $235 \mathrm{DU}$, in a region where the average column usually is of the order of 280 DU. The first event came to an end by 11 May.

[19] In the middle of the above process, when no obvious wave pattern was discernible over the Southern Hemisphere, a low ozone region appeared to the west of the region under study. It entered the region over the South Pacific at $35^{\circ} \mathrm{S}$, $85^{\circ} \mathrm{W}$. This ozone depression corresponded to the next ozone minimum observed in the original wave 5 pattern for the ozone field observed a few days before. During this period this second deep perturbation approached the quasi-stationary minihole. On 9 and 10 May, the perturbation moved in the southeast direction contouring the vanishing stationary minihole (Figure 4c). It must be noted that this perturbation does not appear as a very deep one with respect to the average total ozone values. Except for a very small core under 220 DU, at the peak of the event, the minihole had values of about 230 DU. However, when viewed in the total ozone anomaly maps it does become prominent. In subsequent days the low ozone region, with negative anomalies deeper than -60 DU drifted over the Andes into central/southern Patagonia. This region reached its maximum extent and depth (approx. $-80 \mathrm{DU})$ on 12 May (Figure 4d), after crossing the Andes, with the deepest values over the central Patagonian steppe and just north of the Malvinas (Falkland) Islands. A region of negative anomalies greater than 30 DU, which covered most of Southern Chile, Argentina and the neighboring Argentine Continental Platform, surrounded this low ozone core. However, the core was much smaller than that observed during the first event and it rapidly moved after reaching its maximum depression, at first in an eastward direction over the South Atlantic and then in an east by north east direction (Figures $3 \mathrm{c}$ and $4 \mathrm{e}$ ). This nonstationary behavior is clearly different from the previous case, though it must be noted that the displacement speed of the anomaly had slowed down after crossing the Andes. Furthermore this low ozone event took places at somewhat higher latitudes, but not as high as observed for minihole events over the Northern Hemisphere [James, 1998]. The remains of this minihole appeared to regroup over the Atlantic, off the shores of Northern Patagonia, where a shallower ozone depression remained quasi-stationary through 17 and 18 May (Figures 3d and 4f). Thus the evolution of this second low ozone event can be considered a two-stage process which twice reached very large negative anomalies during its evolution.

[20] Between 10 and 12 May (Figures 4c and 4d) a very deep ozone minihole appeared over the Drake Strait and the Antarctic Peninsula, i.e., close to the southern edge of the region of interest and on the edge of the polar night region. Minimum total ozone values were of the order of $230 \mathrm{DU}$, yet this particular event, when viewed as an anomaly, is even deeper than the first minihole (approx. -100 DU). On the other hand, when compared with the regional variance, its depth was within the standard variance there. It had a short lifetime, moving rapidly toward the East.

[21] Scattered low ozone regions with anomalies with amplitudes between 30 and 45 DU lingered over Northern and Central Argentina and Chile, as well as Uruguay and the tip of Brazil, for a few days. As the second midlatitude minihole weakened and moved away, a prominent ozone ridge followed it, moving in from the Southwest. By 21 and 22 May the Southern Cone was mostly covered by positive ozone anomalies, as much as 50-60 DU above the mean (Figure 4g).

[22] At the end of the month, starting 26 May a low ozone region appeared between the Antarctic Peninsula and the eastern South Pacific (Figures 3e and 3f). This low ozone region extended rapidly and a low ozone core with values between -60 and -80 DU anomaly appeared over the central Patagonia and southern Pampas. This minihole rapidly moved in a Northeast direction and vanished over the South Atlantic to the East of Uruguay by 2 June. This 


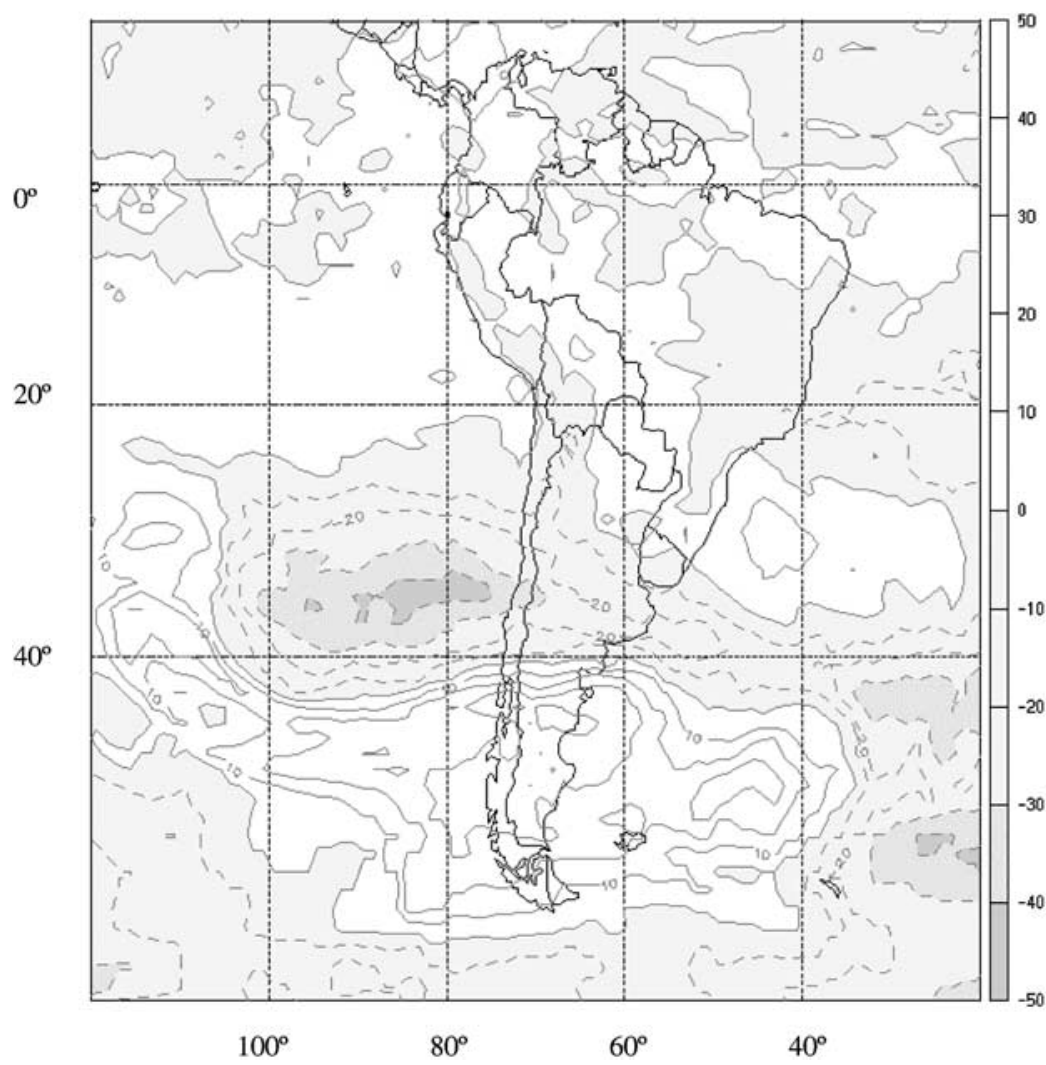

b DU

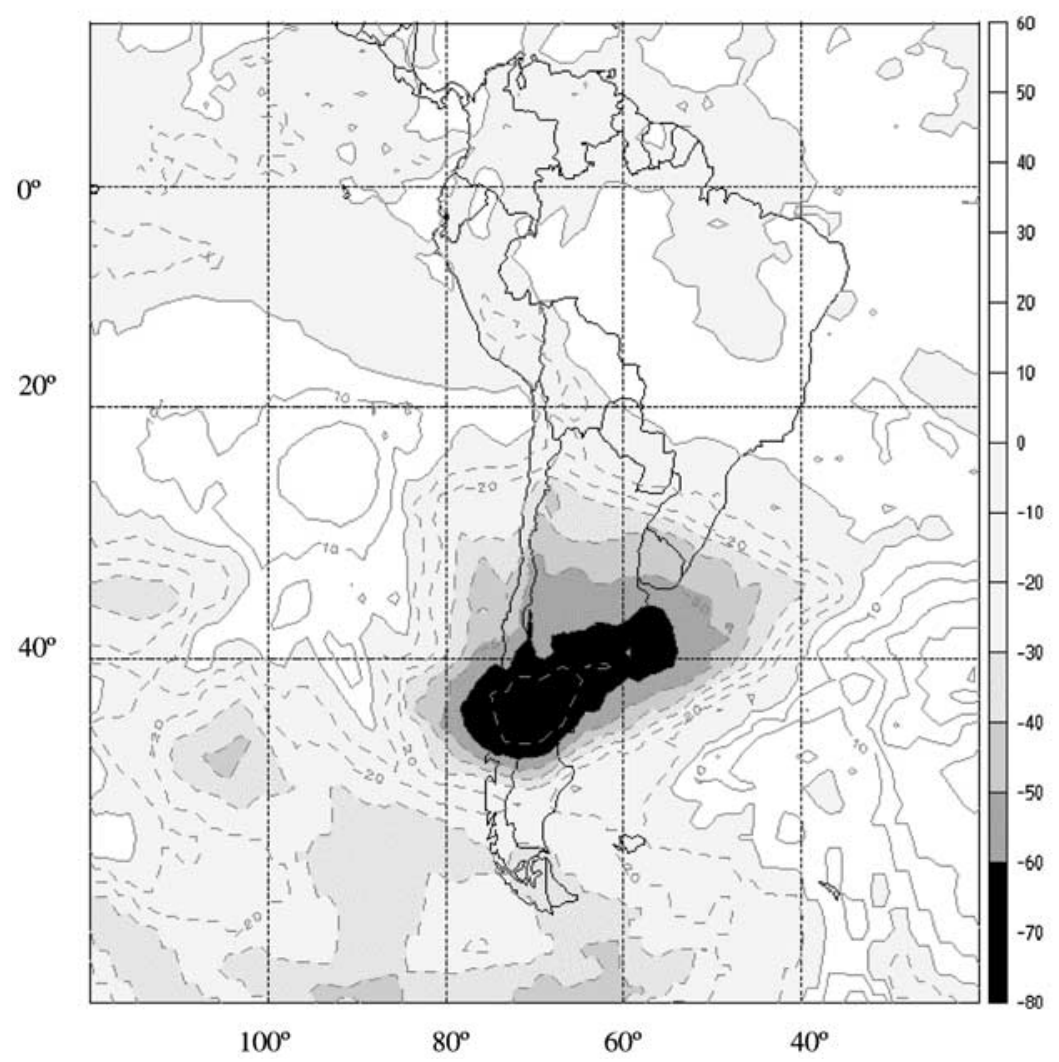

Figure 4. Total ozone anomaly fields (in DU) over South America and adjacent seas during May 1997: (a) 1 May, (b) 8 May, (c) 10 May, (d) 12 May, (e) 14 May, (f) 18 May, and (g) 21 May. 

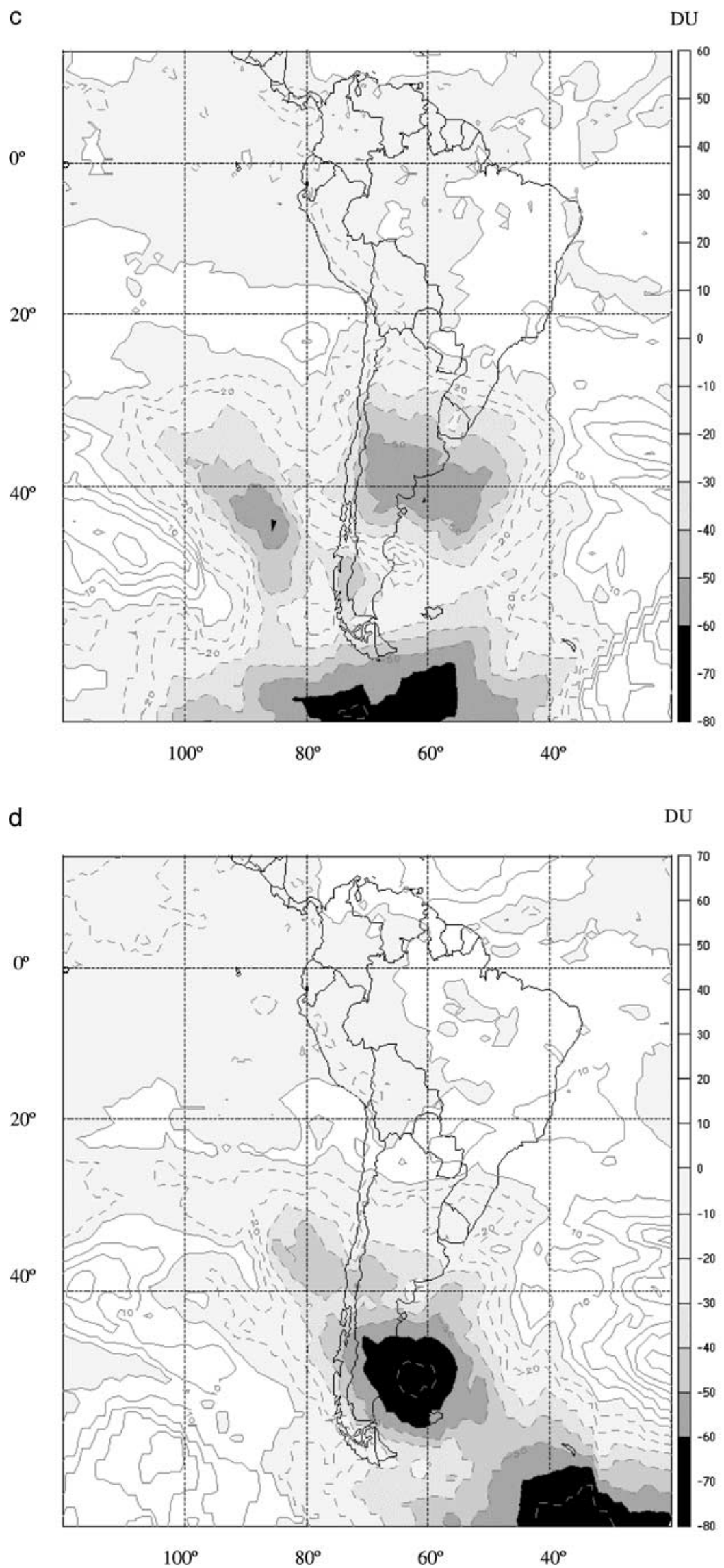

Figure 4. (continued) 

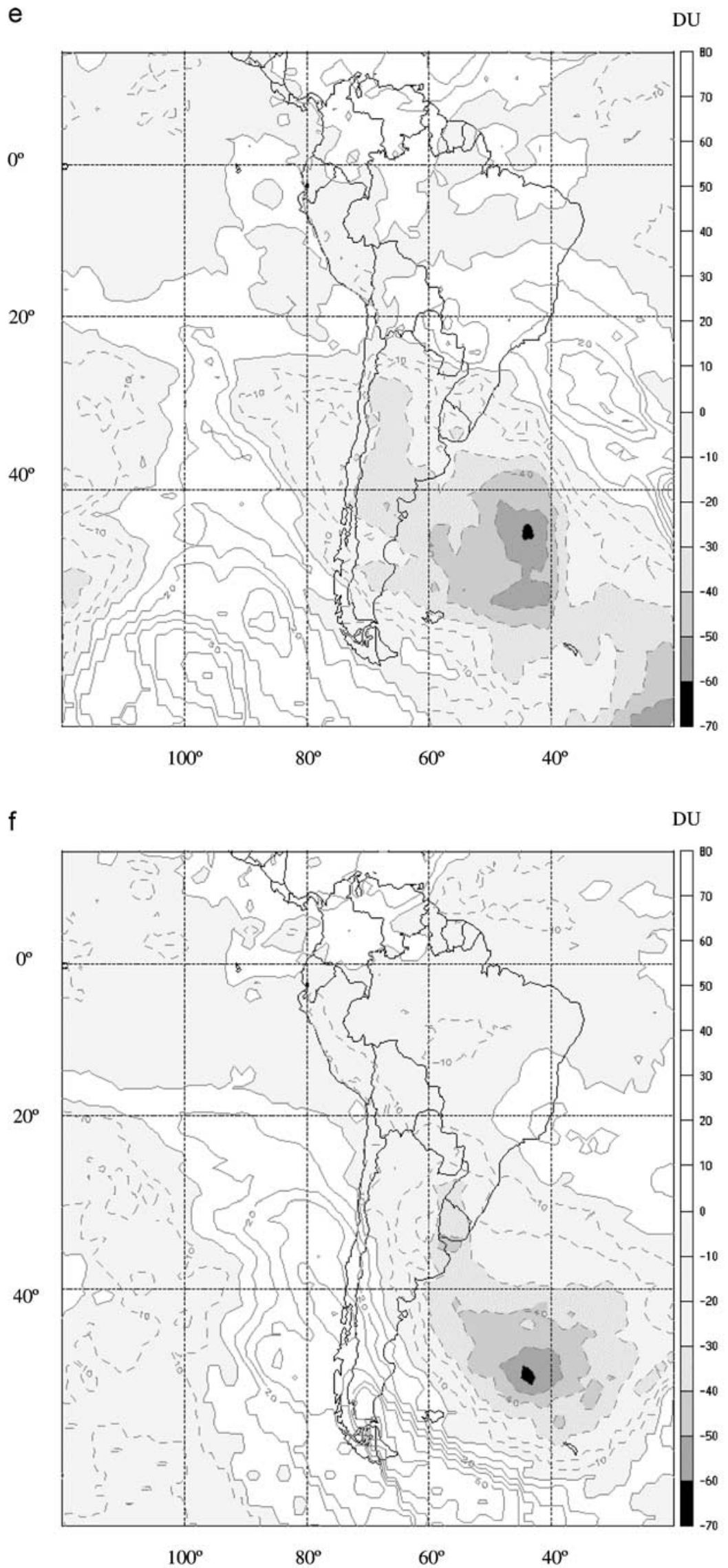

Figure 4. (continued) 
g

DU

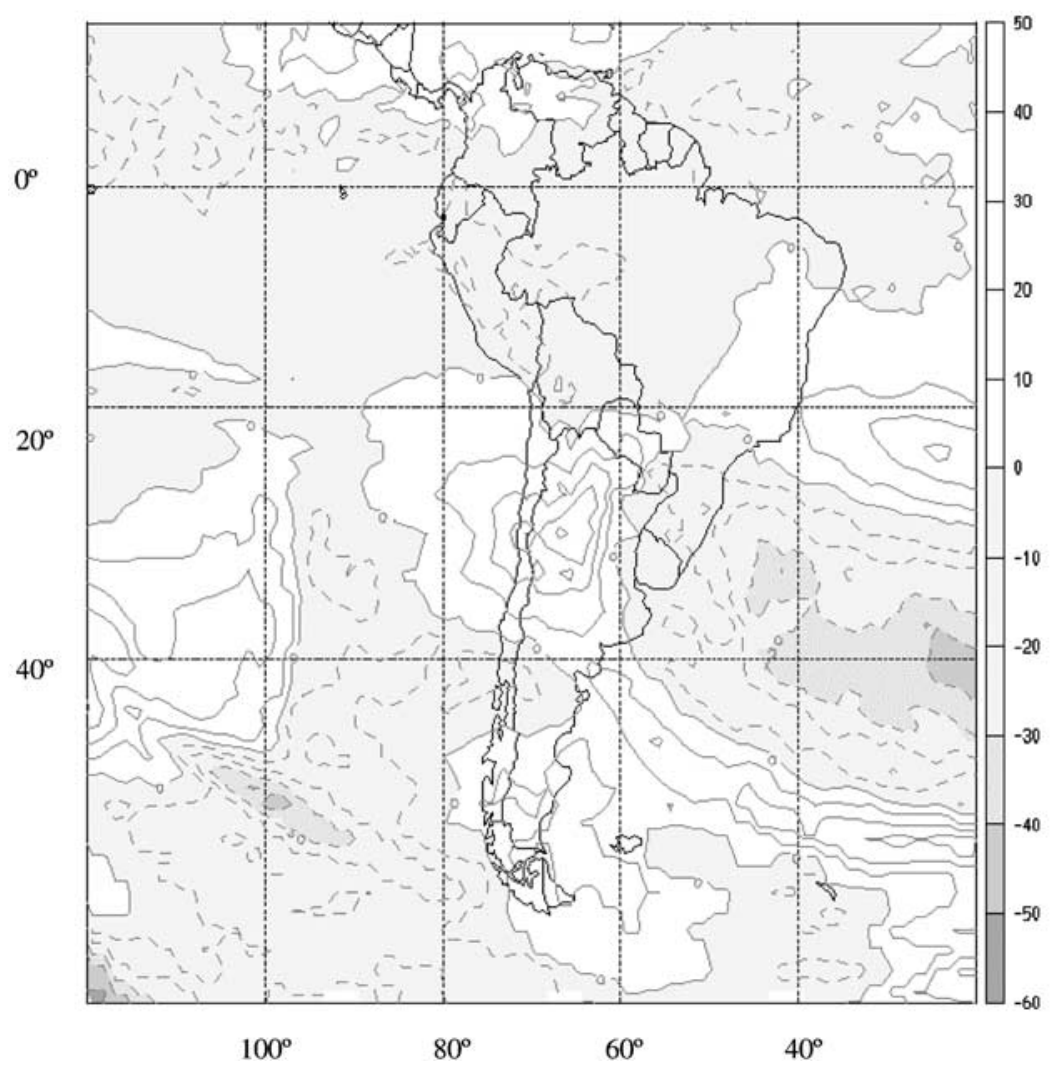

Figure 4. (continued)

process went hand in hand with the appearance and growth of a zonal wave 3 to 4 over the hemisphere. This particular event moved in from high latitudes on the edge of the polar night and hence originated close to the polar vortex.

[23] Thus in somewhat more than a month 3 minihole/ ozone minima events occurred in the vicinity of the Southern Cone, each with different characteristics. A fourth one appeared at high latitudes, over the Antarctic Peninsula, just off the edge of the polar night. The first and deepest one, was the largest and presented a quasi-stationary behavior. Its zonal displacement took place at low to mid middle latitudes. The second one, which was smaller and not as deep, had a faster evolution and displacement, just south of the first one. It migrated over a wider latitude range. Finally the third one had an apparent origin at high latitudes, over the Drake Strait and reached its largest magnitude over Patagonia.

[24] The magnitude of the first minihole can be seen in the comparison of the daily standard deviation $\sigma$ of the anomaly climatology with the observed anomalies at selected sites for the period under study. Figure 5 shows the comparison between the daily $2 \sigma$ and the depth of the minihole over Buenos Aires (Figure 5a) and northern Patagonia (Figure 5b) respectively. The plots show that the first minihole event exceeded the $2 \sigma$ level of the climatology throughout its existence at both locations. Furthermore during the second event over Buenos Aires the observations also came close to the $2 \sigma$ level, while over northern Patagonia the values stayed close to the $\sigma$ level. Even during the third event late in May, the available values over Patagonia are again close to $\sigma$. Taking into consideration that this last minihole evolved at greater latitudes, and hence this comparison does not capture its full extent, all three events are to be considered as prominent ones in the statistics of low ozone values over the Southern Cone.

\section{Synoptic Analysis of the Troposphere and Lower Stratosphere During May 1997}

[25] May is a transition month toward the austral winter circulation, and usually the change from summer to winter circulation takes place about the middle of the month. In particular the transition toward the winter circulation is abrupt over the Southern Cone [Schwertfeger, 1951], lasting only a couple of weeks. This transition usually takes place more quickly than the change from winter to summer circulation during the austral spring, the latter change extending over a number of weeks.

[26] As pointed out by Salby and Callaghan [1993] the total ozone column can be modified both by the vertical displacement of the isentropic surfaces that bounds it close to the tropopause and by horizontal advection along this and other isentropic surfaces in the lower stratosphere. Hence the analysis of the synoptic situations during these events can shed light on the causes that resulted in this sequence of uncommon ozone miniholes.

[27] Zonal and meridional surface circulation indices for the region of interest were calculated according to the following relationships: 

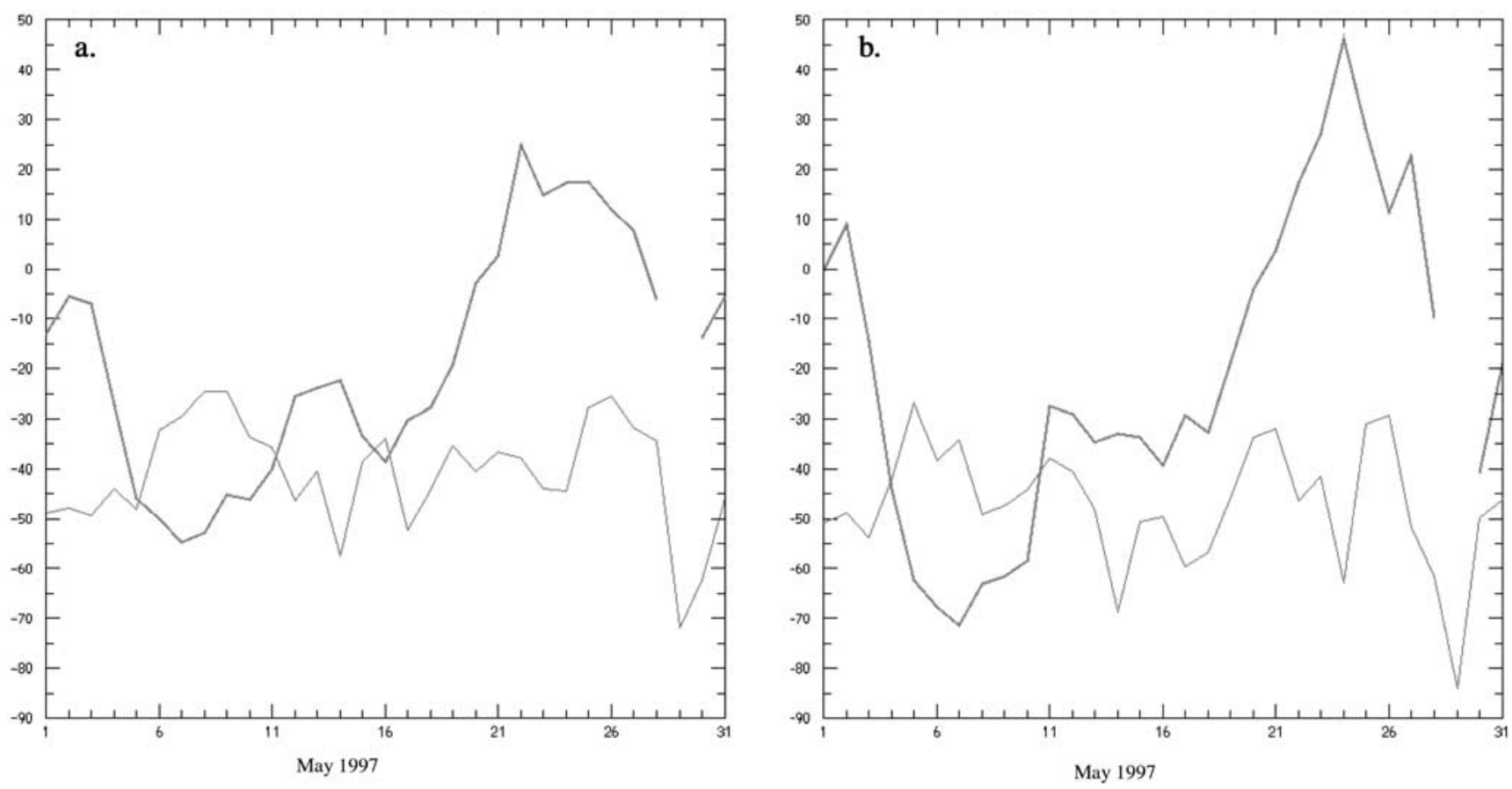

Figure 5. Daily ozone anomaly in DU (green line) over Buenos Aires $\left(34.5^{\circ} \mathrm{S}\right.$ ) (a) and Northern Patagonia $\left(42^{\circ} \mathrm{S}\right)(\mathrm{b})$ and the daily $2 \sigma$ curve (in red, derived from TOMS, also in DU). Note that the first extreme low ozone event is significant even at the $2 \sigma$ level at this time of the year.

1. Meridional Circulation Index MCI: $\Phi\left(40^{\circ} \mathrm{S}, 90^{\circ} \mathrm{W}\right)-$ $\Phi\left(40^{\circ} \mathrm{S}, 40^{\circ} \mathrm{W}\right)$;

2. Zonal Circulation Index ZCI: $\Phi\left(35^{\circ} \mathrm{S}, 70^{\circ} \mathrm{W}\right)-\Phi\left(55^{\circ} \mathrm{S}\right.$, $\left.70^{\circ} \mathrm{W}\right)$

$\Phi$ being the geopotential height at $1000 \mathrm{hPa}$ at the given point (Figure 6).

[28] The basic mean field for the region under consideration is dominated by westerly flows south of approximately $40^{\circ} \mathrm{S}$ and the semipermanent anticyclones over the Atlantic and Pacific Oceans, which also have an impact over continental areas of the South Cone to the north of that latitude. Since April and through early May, the ZCI fell noticeably. On three occasions during May and June 1997 the ZCI even reached negative values, i.e., a reversal of the zonal flow. It recovered only during the first fortnight of June. A sustained MCI together with the anomalous ZCI points to the considerable degree of perturbation to the mean flow at the time. Such a breakdown can be indicative of blocking events. The basic pattern was indeed strongly perturbed during the period under study by a sequence of three blocking events. The approximate dates for these events are 2-9 May, 14-20 May and 30 May-5 June.

[29] It should be noted that blocking events in the Southern Hemisphere have a somewhat different behavior from the ones in the Northern Hemisphere [Coughlan, 1983]. There are three main regions where blocking events tend to occur over the Southern Hemisphere, whereas there are two in the Northern Hemisphere. The main one is located south of New Zealand, and the other two to the southeast of South America and over the southern Indian Ocean [van Loon, 1956; Taljaard, 1972; Trenberth and Mo, 1985; Sinclair, 1996, and references therein]. Blocking events in the Southern Hemisphere tend to occur between 40 and $60^{\circ} \mathrm{S}$. These events are not as intense and are shorter-lived than in the Northern Hemisphere. Finally it should be noted that blocking events are more frequent in spring and autumn, i.e., there exists a bimodal time distribution rather than the single spring maximum over the Northern Hemisphere. A number of studies have been carried out regarding various aspects of blocking events near Southern South America [e.g., Grandoso and Nuñez, 1955; Rutllant and Fuenzalida, 1987; Berbery and Nuñez, 1989].

[30] The surface temperatures give an assessment of the extent of the perturbations during May 1997. The surface temperature over Buenos Aires started to climb on 4 May, with maxima close to or above $30^{\circ} \mathrm{C}$ on 7-9 May. According to the Argentine Servicio Meteorologico Nacional (S.M.N.) 1981-1990 statistics, the May maximum temperature monthly mean is $19.0^{\circ} \mathrm{C}$, the monthly mean is $14.3^{\circ} \mathrm{C}$

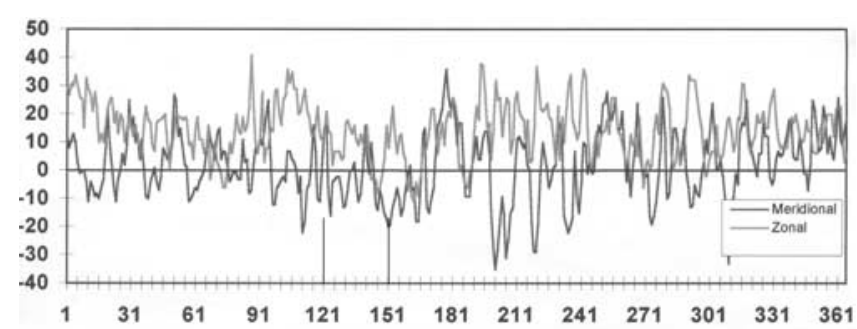

Figure 6. Evolution of the zonal and meridional flow indices over southern South America during 1997 given by Meridional Circulation Index MCI (blue line): $\Phi\left(40^{\circ} \mathrm{S}\right.$, $\left.90^{\circ} \mathrm{W}\right)-\Phi\left(40^{\circ} \mathrm{S}, 40^{\circ} \mathrm{W}\right)$ and Zonal Circulation Index ZCI (red line): $\Phi\left(35^{\circ} \mathrm{S}, 70^{\circ} \mathrm{W}\right)-\Phi\left(55^{\circ} \mathrm{S}, 70^{\circ} \mathrm{W}\right)$. The study period is for day 121 to day 151 . 
and the monthly mean minimum temperature is $10.3^{\circ} \mathrm{C}$. The temperature maximum decreased to $20.5^{\circ} \mathrm{C}$ after the first blocking. However, it climbed again to high values, i.e., $27^{\circ} \mathrm{C}$, in the middle of the second blocking. It then fell to $13^{\circ} \mathrm{C}$ between the second and third blocking events. During the last event, it climbed for the last time to values above the monthly mean, but not as significantly as in the previous cases, returning a few days later, in June, to the mean behavior. To the best of our knowledge, even though successive blocks can be rather frequent, there are no references in literature dealing with so well defined blocking situations, with significant persistence, separated by such reduced intervals over the South Cone and adjacent oceans. In the present analysis special attention will be placed on the consequences of these tropospheric events upon the tropopause and the lower stratosphere.

[31] The first two most significant blocking events will now be discussed in detail, pointing to the differences inherent to each. The last event associated with a weaker, more "standard" ozone minihole will only be considered briefly.

\subsection{First Blocking Event}

[32] The first blocking with which the deepest minihole is associated began around 2 May (Figure 7) and lasted till 9 May. The peak of the event was 7 May (Figure 8). At this time the geopotential height field at $1000 \mathrm{hPa}$ (Figure 7a), shows a distinct trough $\mathrm{T}_{1}$ over the Pacific to the west of Chile in between 2 ridges $\left(R_{1}\right.$ and $R_{2}$ respectively). It must be noted that on previous days these ridges were not as well defined. The low $\mathrm{L}_{1}$ toward the north of $\mathrm{R}_{2}$ is located at $37^{\circ} \mathrm{S} 105^{\circ} \mathrm{W}$, while another low $\mathrm{L}_{2}$ can be located to the west of the Antarctic Peninsula. The $500 \mathrm{hPa}$ map (Figure $7 \mathrm{~b}$ ), representative of the middle troposphere region shows similar features slightly to the east and north of these. The field at $50 \mathrm{hPa}$ (Figure 7c), representative of the upper limit of the lower stratosphere show the signature of troughs and ridges colocated with the ones observed at $500 \mathrm{hPa}$. Even if these perturbations are somewhat faint, they do show that the signature of the tropospheric disturbance can reach such a height, as the inspection of a longitude height plot (not shown) can confirm. This points to the strong barotropic nature of this event. The tropopause pressure field (Figure 7d) has high values, i.e., a low tropopause, over the lows $\mathrm{L}_{1}$ and $\mathrm{L}_{2}$. Consequently the tropopause temperature (Figure 7e) shows a warming over the trough axis $T_{1}$ and the associated lows and cooling along the ridges $R_{1}$ and $R_{2}$. There is also a significant tropopause temperature gradient in the vicinity of $35^{\circ} \mathrm{S}$. The potential vorticity field (PV, not shown) at the $380 \mathrm{~K}$ isentropic surface, i.e., just above the tropopause, shows a significant decrease in its strength (a reduced absolute value since $\mathrm{PV}$ is negative in the Southern Hemisphere) over $T_{1}$. Low PV values such as these could be associated with transport of tropical/subtropics air into lower midlatitudes. At this time the axis of the trough and ridges have approximately a $45^{\circ}$ slope with respect to the N$\mathrm{S}$ axis. When the blocking pattern became evident on this date the low ozone region described in section 3 was located on the leading edge of the trough, along the $T_{1}$ axis (Figure $3 f$ ), just off the ridge $R_{1}$. In this part of the trough the advection of negative vorticity maximizes. The ozone depression's largest amplitude at this time was of the order of $50 \mathrm{DU}$, just off the coast of Chile at $35^{\circ} \mathrm{S}$.
[33] From 2 to 7 May, the ozone minihole evolved to reach its maximum extent and depth (Figure 4f). At 1000 $\mathrm{hPa}$ (Figure $8 \mathrm{a}$ ) the systems move eastward since 2 May. Two high-pressure zones can be identified north of $40^{\circ} \mathrm{S}$, over the Atlantic and the Pacific Oceans respectively. There is a weak trough between these two zones. South of $40^{\circ} \mathrm{S}$ the flow is quasi-zonal. At $500 \mathrm{hPa}$ (Figure 8b) the low $\mathrm{L}_{1}$ moved steadily eastward, while the trough $\mathrm{T}_{1}$ tended to align itself with the meridian. The ridge $R_{1}$, enhanced by this displacement, becomes almost parallel to the Andes. At the same time $\mathrm{L}_{2}$, rapidly moved off to the South Atlantic in an east-northeast direction. The circulation had different behaviors to the north and south of $50^{\circ} \mathrm{S}$. To the south the flow remained almost zonal, but to the north there was a strong northwesterly flow, near $40^{\circ} \mathrm{S}, 80^{\circ} \mathrm{W}$, which weakens to the north. It is interesting to note that the low pressure system and the trough and ridge systems remained aligned in the vertical at least up to $50 \mathrm{hPa}$ (Figure 8c) during this evolution. By the 7 May, the ozone depression (Figure 8f) was located almost over the crest of ridge $\mathrm{R}_{1}$, and continued to deepen despite the fact that maximum tropopause height (Figure 8d) was reached on 6 May. The tropopause had cooled significantly during this period (Figure 8e), with a significant rise in height in a wide region over which the ozone minimum occurred. Both the tropopause height and temperature had very sharp gradients on the southern edge of the bulge that extended south over the Southern Cone. Tropopause temperatures below $200 \mathrm{~K}$ occurred at this time over an important region covering Uruguay, central and northern Chile and Argentina. It must be noted too that the weak PV region that at the beginning was linked to the tropics became isolated and was surrounded by regions of stronger PV. This weak PV region is well correlated with the low ozone region. However, it must be kept in mind that the extreme low ozone values registered at this time were far lower than those observed in tropical regions from where the weak PV air came, to the north of the minihole (Figure 4f), during the process described here. Hence the ozone depression is not merely the result of transport of tropical/ subtropical air into the region. This will be further discussed in sections 5 and 6 .

[34] After the 7th $\mathrm{L}_{2}$ started to weaken at $500 \mathrm{hPa}$. At the same time the flow at $50 \mathrm{hPa}$ became more zonal. The tropopause remained high but not quite as high as before. At $1000 \mathrm{hPa}$, at midlatitudes, it was possible to see the onset of the next trough that led to the second low ozone event. Indeed by 12 May a similar synoptic situation started to develop, resulting in the sequence of low ozone events described in section 3 .

\subsection{Second Blocking Event}

[35] The meteorological situation was rather complex during the weakening and demise of the first blocking and the onset of the 2nd blocking, a few days later. It is under these conditions that the second minihole matured, and that the high-latitude one made a brief appearance along the southern border the region of interest (Figures 9 and 10).

[36] The second major blocking event began around 12 and 13 May and lasted till 20 May approximately. At 1000 $\mathrm{hPa}$ a trough axis appeared to the West of the Andes, deepening the following day, together with a southern displacement of an anticyclone located over the South 
CANZIANI ET AL.: IMPACTS OF TROPOSPHERIC SYNOPTIC PROCESSES ACL $\quad \mathbf{2}-13$
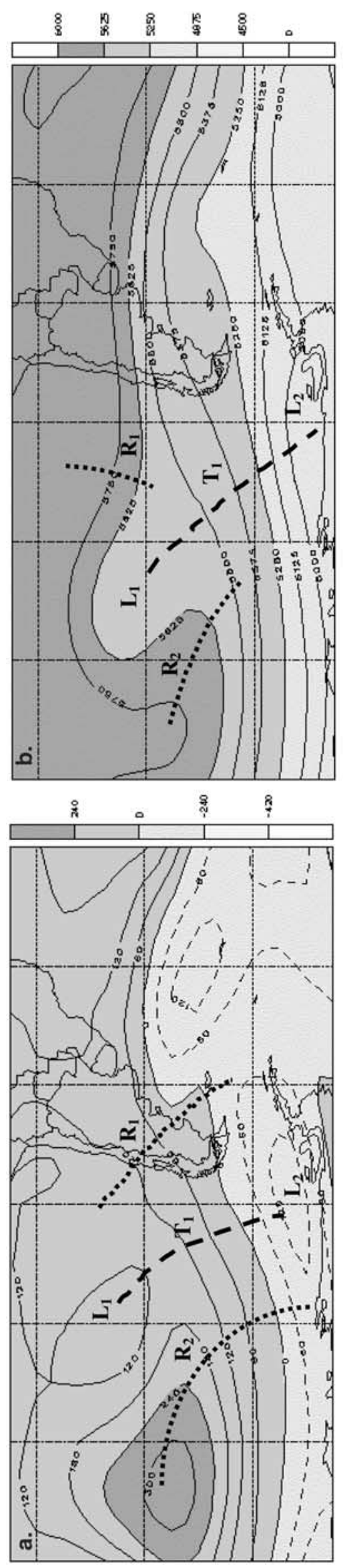

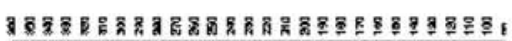
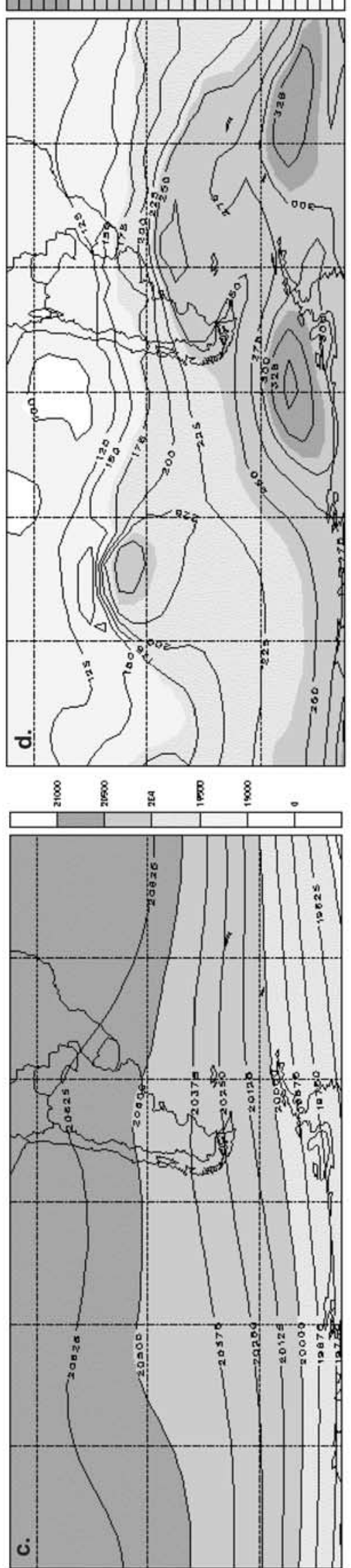

ฮㅇ 8 \& 8 ค
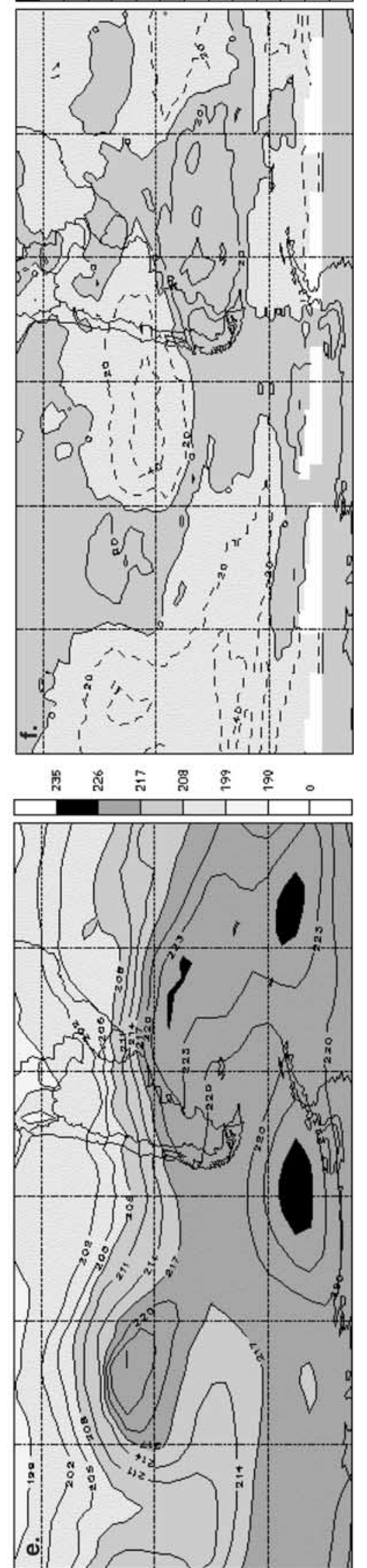

$\stackrel{\oplus}{\Phi}$

里

晜

궁

㫕

군

है

$\dot{\mathscr{\theta}}$

谂

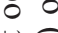

(당

蒙

¿

클

응

क्ठ है

용

モี

를

\&

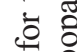

సิํํ

의

อี ฮే

도

를유

过

票

胥

क 8

ํํㅇ

क

ㄷㅇㅇㅇ

承 
ACL 2 - 14 CANZIANI ET AL.: IMPACTS OF TROPOSPHERIC SYNOPTIC PROCESSES

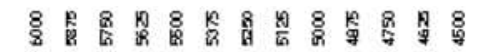

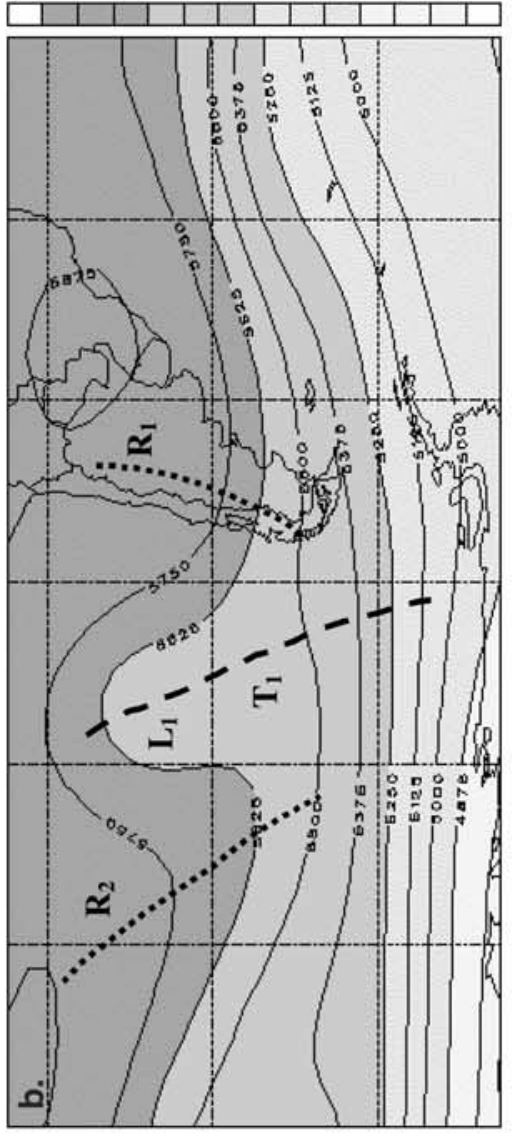

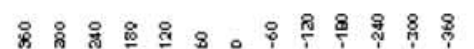

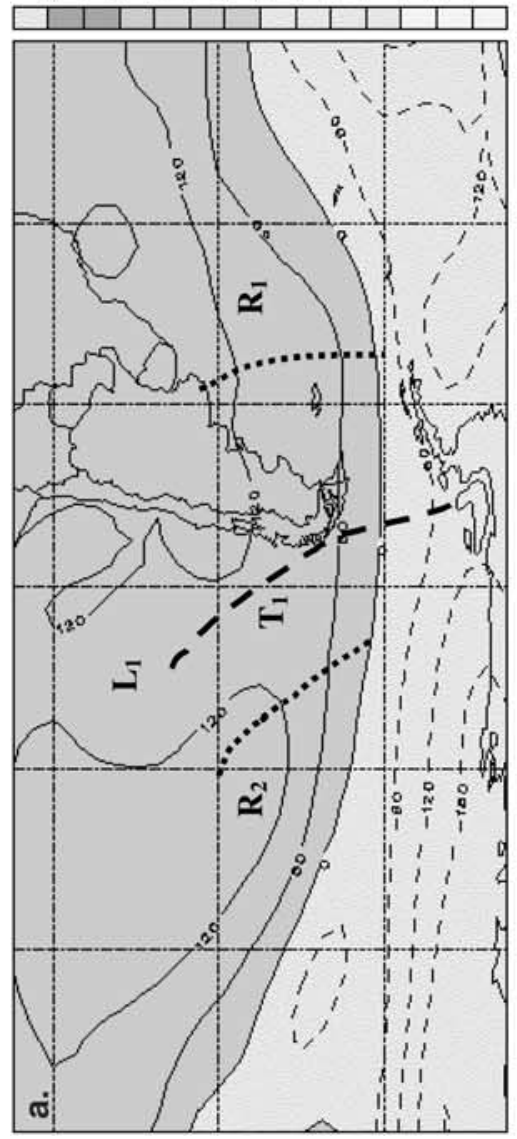

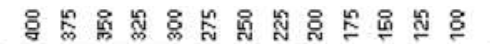

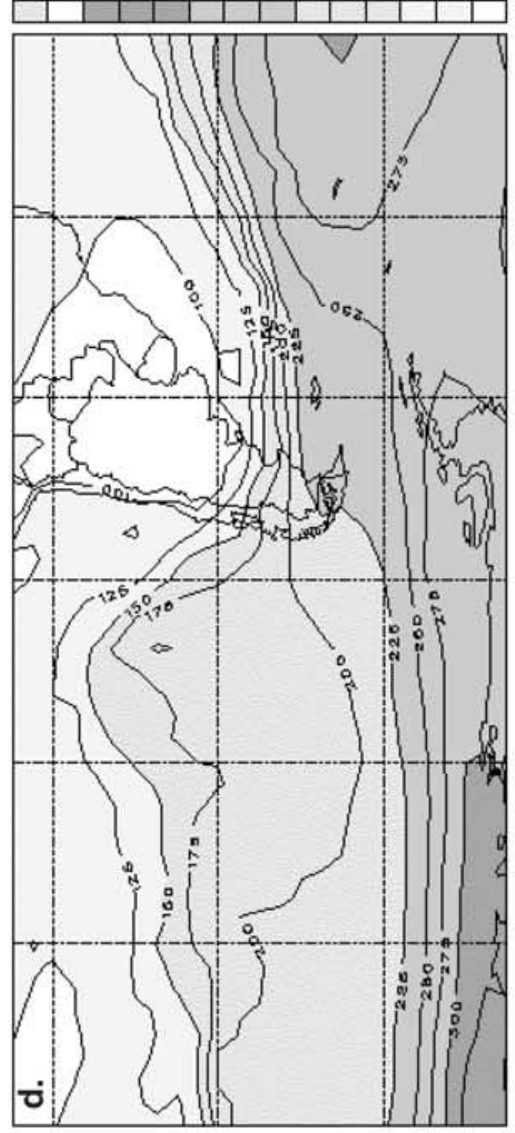

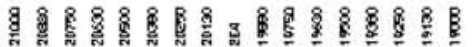

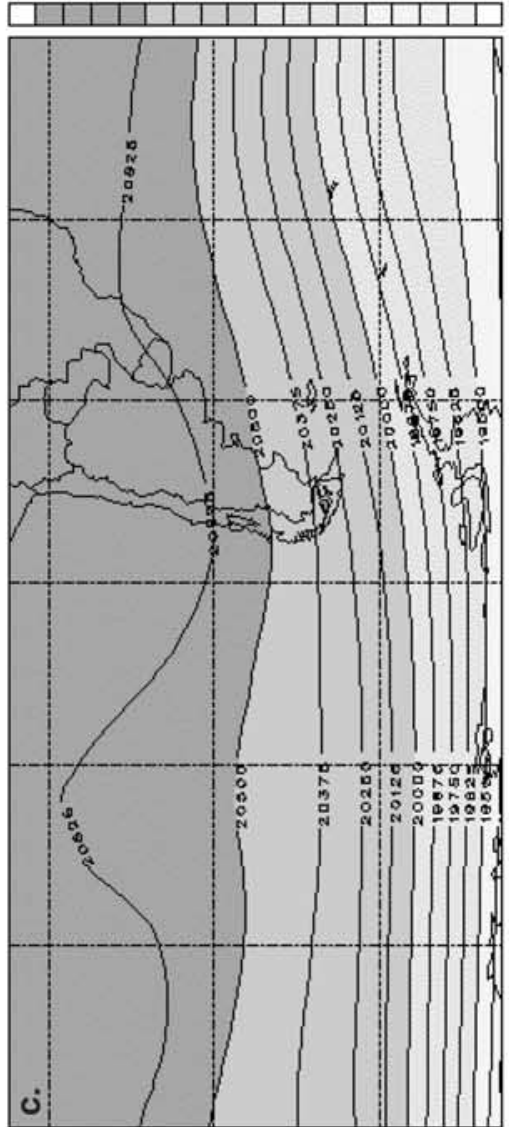

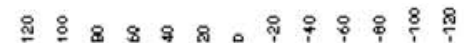

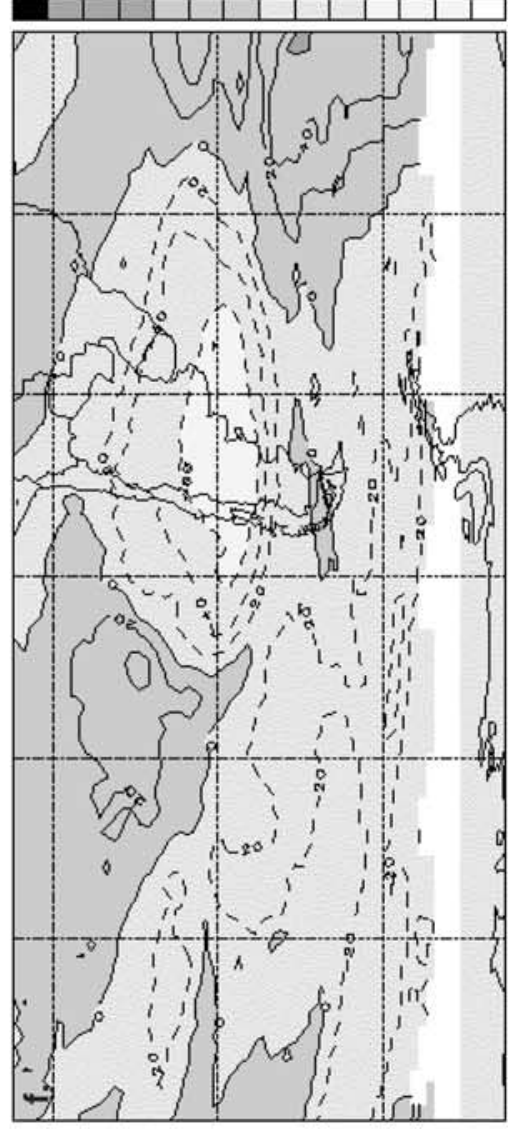

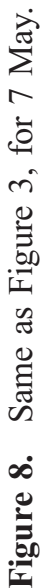
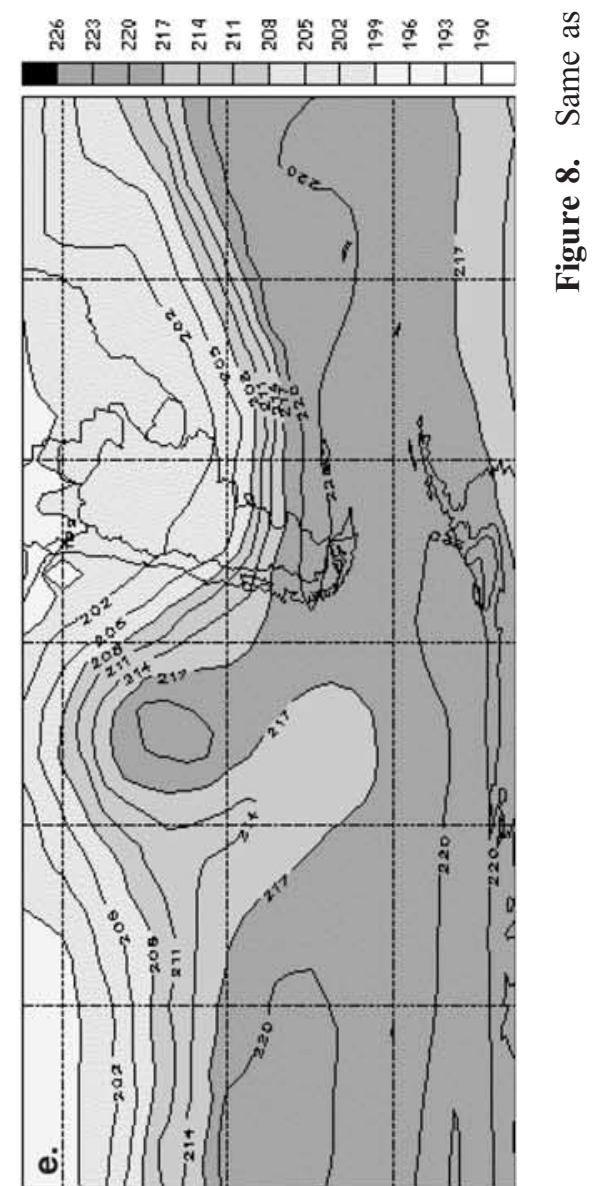
Atlantic to the east of the continent (Figure 9a). The beginning of this event is well identified at $500 \mathrm{hPa}$ (Figure 9b). At $50 \mathrm{hPa}$ (Figure 9c) a similar pattern can also be seen, particularly the ridge over the South Atlantic and Argentina. The troughs and ridges deepen on 13 May. These ridges and troughs were displaced $10^{\circ}$ to the East with respect to the beginning of the 1 st blocking. By the 14th the blocking has fully developed in height. Inspection of the $50 \mathrm{hPa}$ geopotential height map shows that the troughs and ridges are slightly displaced with respect to the $1000 \mathrm{hPa}$ ones. Thus this event did not have the distinct barotropic signature of the first one: the fields' main features appear displaced with height toward the west, pointing to the baroclinic nature of the event. Furthermore at $50 \mathrm{hPa}$ the ridges and troughs were more prominent than for the 1 st event and the geopotential height had a stronger meridional shear in this case, indicating that this perturbation penetrated with greater strength into the lower stratosphere. A low and warm tropopause (Figures 9d and 9e) can be seen over the southern South Pacific over the trough. At midlatitudes, over the South Atlantic another low, warm tropopause region is also present. Two regions of high, cool tropopause separate these regions, one to the south and one to the north. The ozone anomaly field (Figure 9f) has a minimum in the region of intersection of these four tropopause regions.

[37] At $1000 \mathrm{hPa}$ a deep trough could be seen on 17 May with two low pressure systems and two high pressure systems over each ocean (Figure 10a). The center of the South Pacific anticyclone had shifted toward a more southern location from its usual position. The meridional flux maximized on 17 May at the peak of the blocking. It is interesting to note that at $500 \mathrm{hPa}$ (Figure 10b) the ridge drastically changed its tilt with respect to the meridian during this evolution. While the following trough and ridge more or less maintained a similar westward inclination with respect to the meridian, the equatorward side of the ridge moved eastward more quickly than the southern end. On 17 May this ridge had an eastward tilt with respect to the meridian. At $50 \mathrm{hPa}$ the same succession of trough and ridges can also be seen (Figure 10c). This event is far stronger and extends further south than the first event.

[38] Starting 18 May the system is no longer quasistationary as the subsequent ridge moved toward the East, and the whole blocking structure slowly vanished in subsequent days. It must be noted that the lower stratospheric PV followed this process but no important variability could be observed.

[39] The tropopause height (Figure 10d) and temperature (Figure 10e) did not show as significant and orderly a response to this blocking situation as in the previous case. The tropopause isotherms and isobars north of $50^{\circ} \mathrm{S}$ kept a fairly zonal structure throughout the first part of the event, with a weaker meridional gradient. Major perturbations developed poleward of that latitude. During this event the tropopause temperatures were warmer in general, the corresponding perturbation was not as cold and the thermal gradient was not as pronounced along the edge of the perturbed region. In other words, the tropopause appeared to be a node in the behavior of the geopotential height perturbation field. The ozone minimum now coincides with a relatively sharp tropopause gradient region over the South Atlantic (Figure 10f), as the tropopause rises toward the lower latitudes. A prominent ozone ridge was found to the west of the continent over the low tropopause region.

[40] It must be noted however that while the blocking event continued to develop and strengthen through that date, the maximum ozone depression was reached on 10-12 May, i.e., just before the onset of this blocking event. The minihole center, on 14 May, was located as before on the leading edge of the trough, between $30-60^{\circ} \mathrm{S}$ and $60-$ $40^{\circ} \mathrm{W}$. It remained at this location through 17 May, the low ozone region adopting the shape of the southern end of the ridge. As discussed in the previous section, after reaching the maximum ozone depression on that period this low ozone area continued an easterly motion, and its remnants participated in the formation of the partially reinforced ozone minimum as this blocking event strengthened.

\subsection{Third Blocking Event}

[41] This final situation cannot be considered a truly typical blocking event due to the displacements of low and high pressure systems. The system centers were located further south since, for example at $500 \mathrm{hPa}$, these were found south of $40^{\circ} \mathrm{S}$. There is no evidence whatsoever of these systems at $50 \mathrm{hPa}$. The tropopause suffered their influence south of $50^{\circ} \mathrm{S}$. The associated ozone depressions occurred at higher latitudes close to subpolar regions. These moved rapidly together with the troughs and ridges. Such an event has characteristics more common than the ones reported above.

\section{Trajectory Analysis}

[42] In order to reach a better understanding of the contributions by the horizontal advection to the ozone field during these episodes, trajectory calculations were carried out for the first and second minihole events. These were obtained using the Goddard Automailer system, which run, for the present calculations, with the NCEP reanalysis products. The calculations were carried out at two isentropic levels, one close to the tropopause at $380 \mathrm{~K}$ and the other close to the middle stratosphere at $550 \mathrm{~K}$, i.e., in the vicinity of $50-60 \mathrm{hPa}$. These calculations included 10-day backward and forward trajectories, before and after each event, originated every 5 degrees between 10 and $55^{\circ} \mathrm{S}$, along 295 and $305^{\circ} \mathrm{E}$ longitudes, for the first and second events, respectively. The origin longitudes were chosen so that first set is centered on the meridional axis of the 7 May minihole (Figures 11 and 12) and the second one on 14 May ozone depression (Figures 13 and 14). As usual it must be remembered that trajectories equatorward of $20^{\circ} \mathrm{S}$ should be viewed with caution due to limitations of assimilated winds in equatorial regions. Each figure includes plots of the latitude-longitude location of the parcels during the 20 days of the samples, as well as the PV and height (in $\mathrm{km}$ ) during the parcel evolution.

[43] The trajectory plots for the first event show the strong meridional perturbations to the mean flow extending from the tropics all the way to $40-50^{\circ} \mathrm{S}$, throughout the 20 day period. For example, near the tropopause, at $380 \mathrm{~K}$ (Figure 11a), the trajectory originated at $55^{\circ} \mathrm{S}$ (light green) shows latitudinal oscillations of about $10-12^{\circ}$ before and after this day. Further north, air parcels originally located between 20 and $30^{\circ} \mathrm{S}$ were displaced as far as $45^{\circ} \mathrm{S}$ (orange) 
ACL 2 - 16 CANZIANI ET AL.: IMPACTS OF TROPOSPHERIC SYNOPTIC PROCESSES

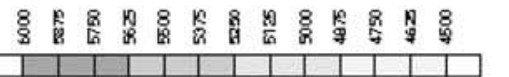

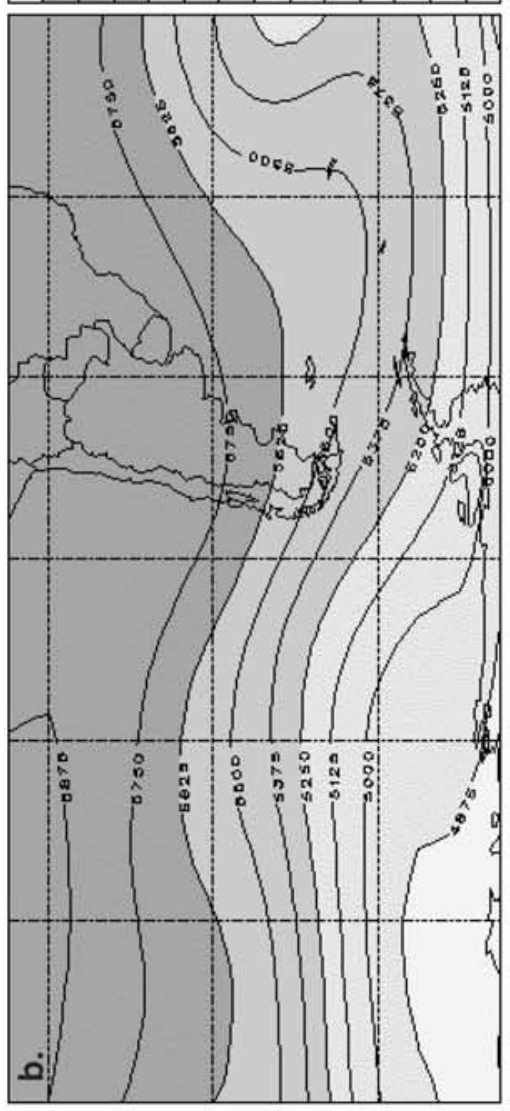

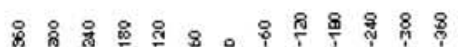

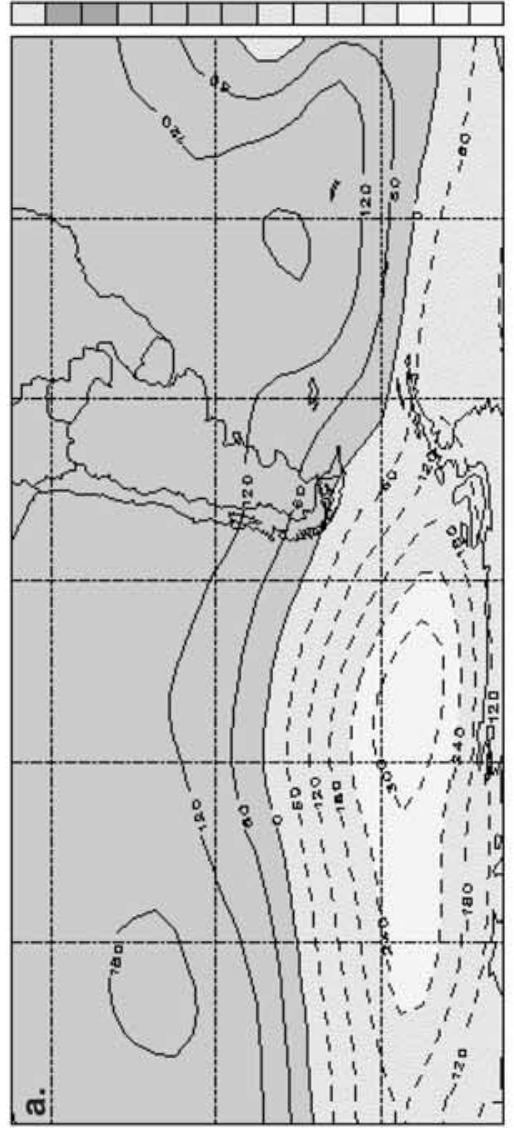

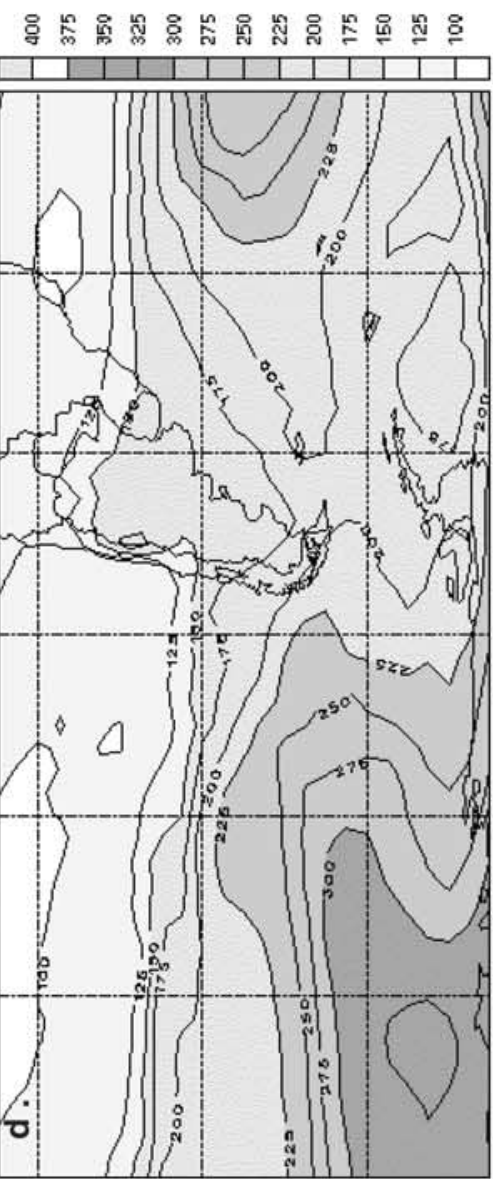

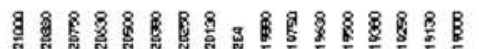
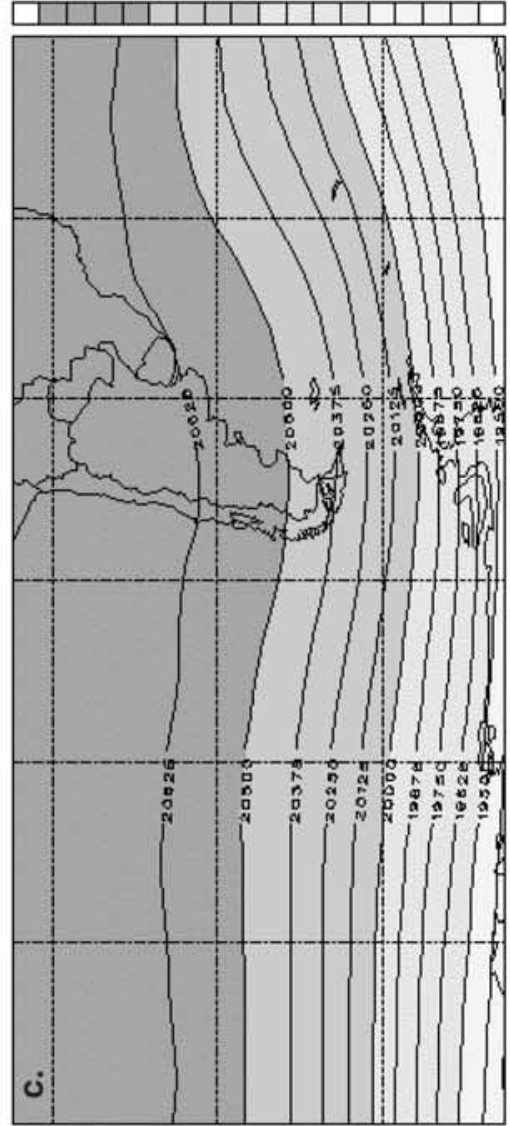

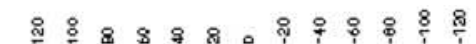
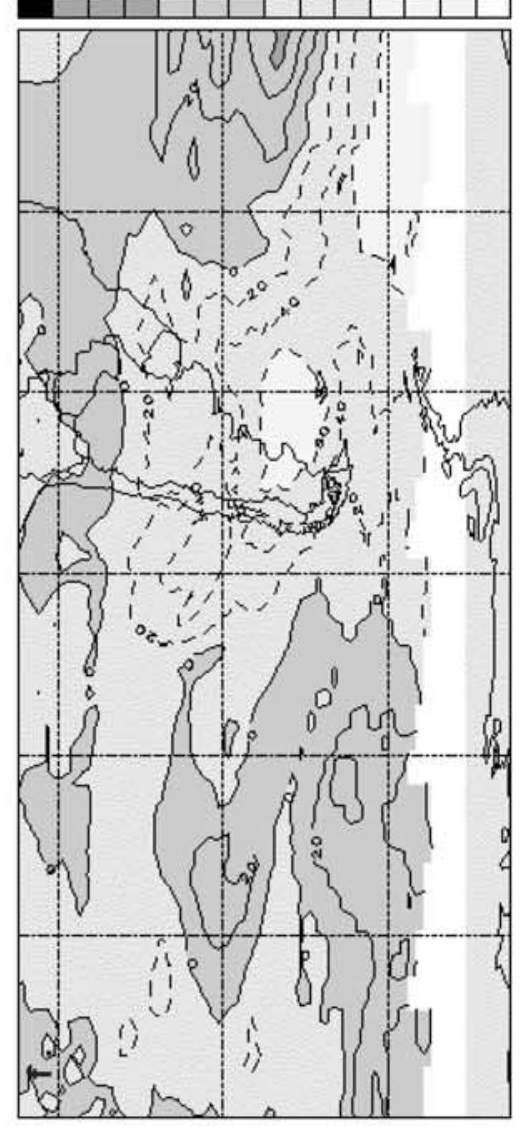

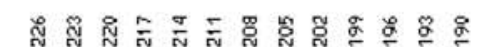

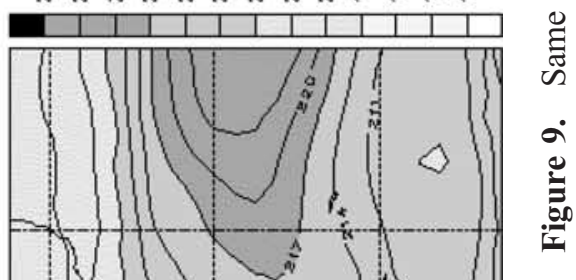

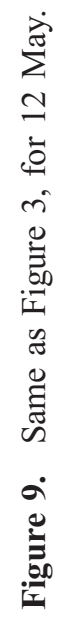


CANZIANI ET AL.: IMPACTS OF TROPOSPHERIC SYNOPTIC PROCESSES $\quad$ ACL $\quad \mathbf{2}-17$

8 8

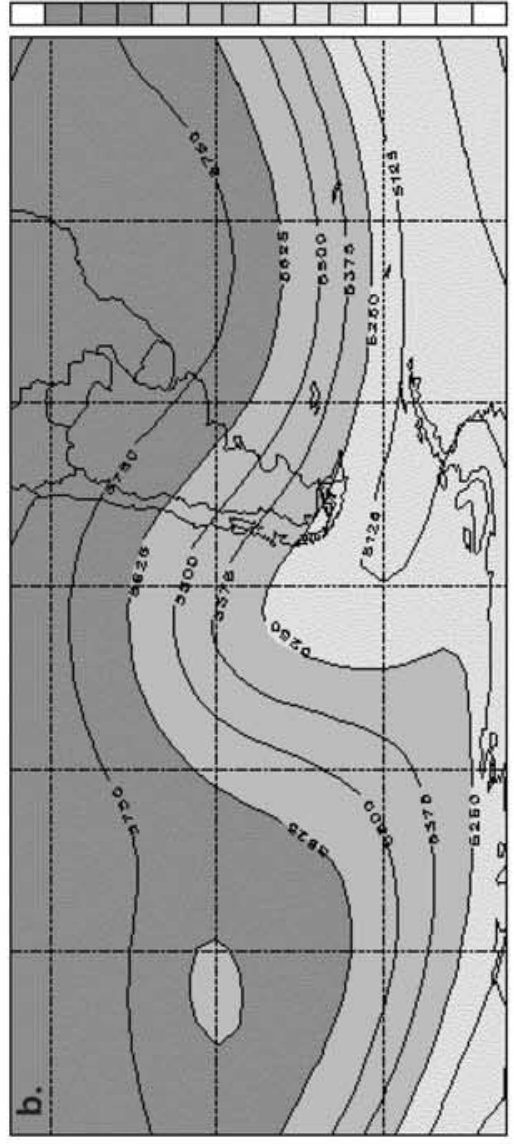

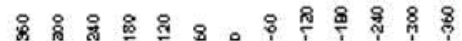

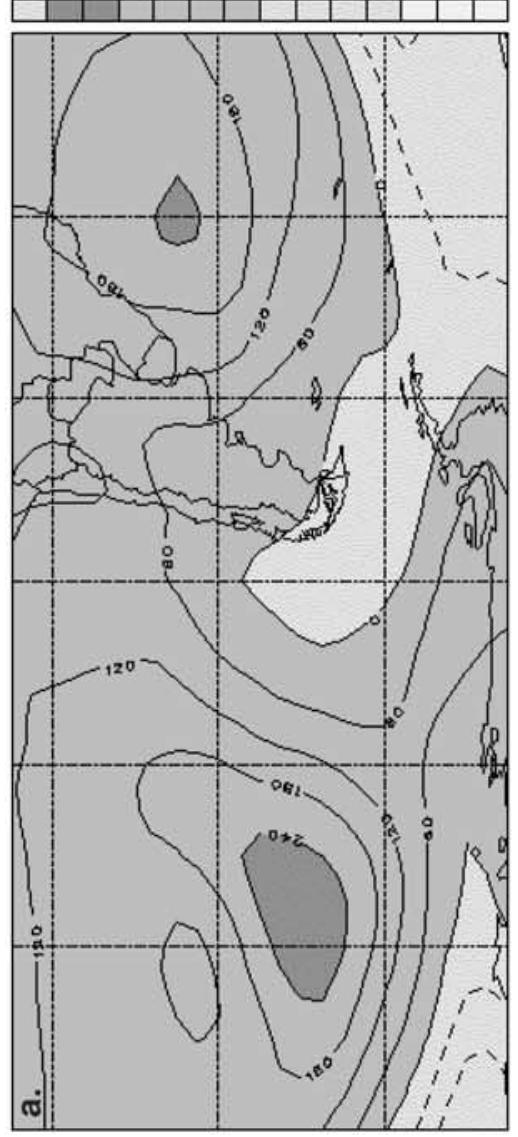

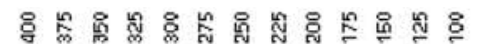

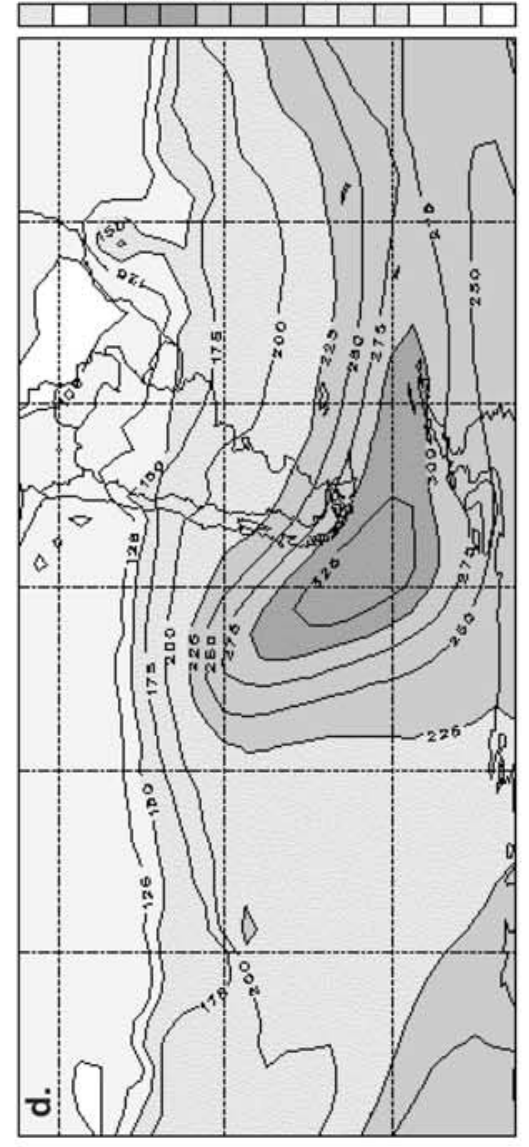

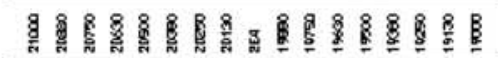

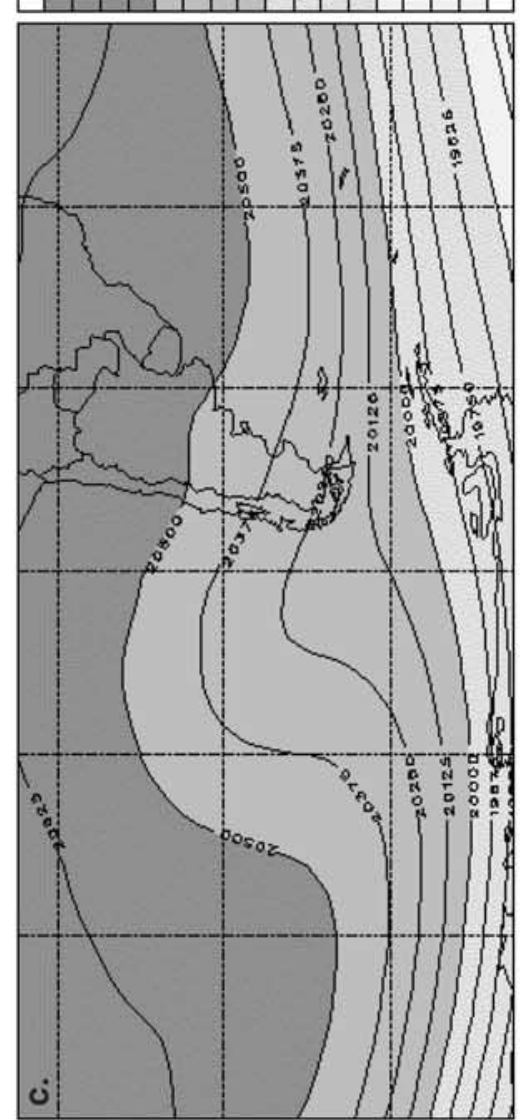

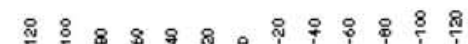

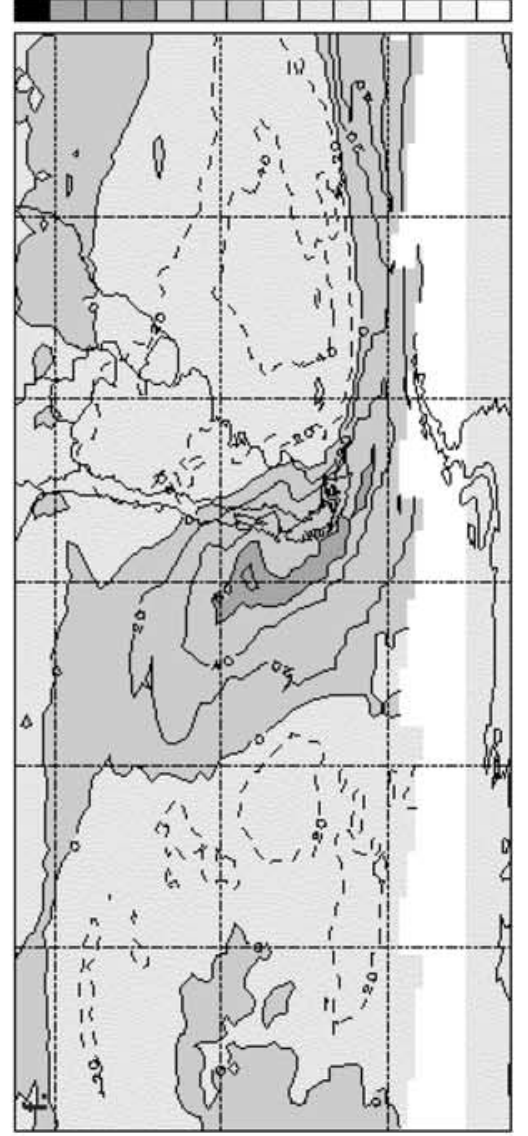

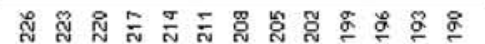

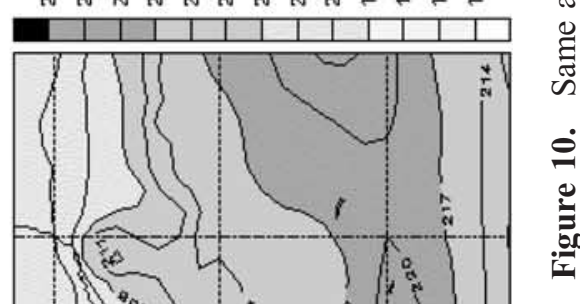

$\stackrel{\circ}{0}$ 

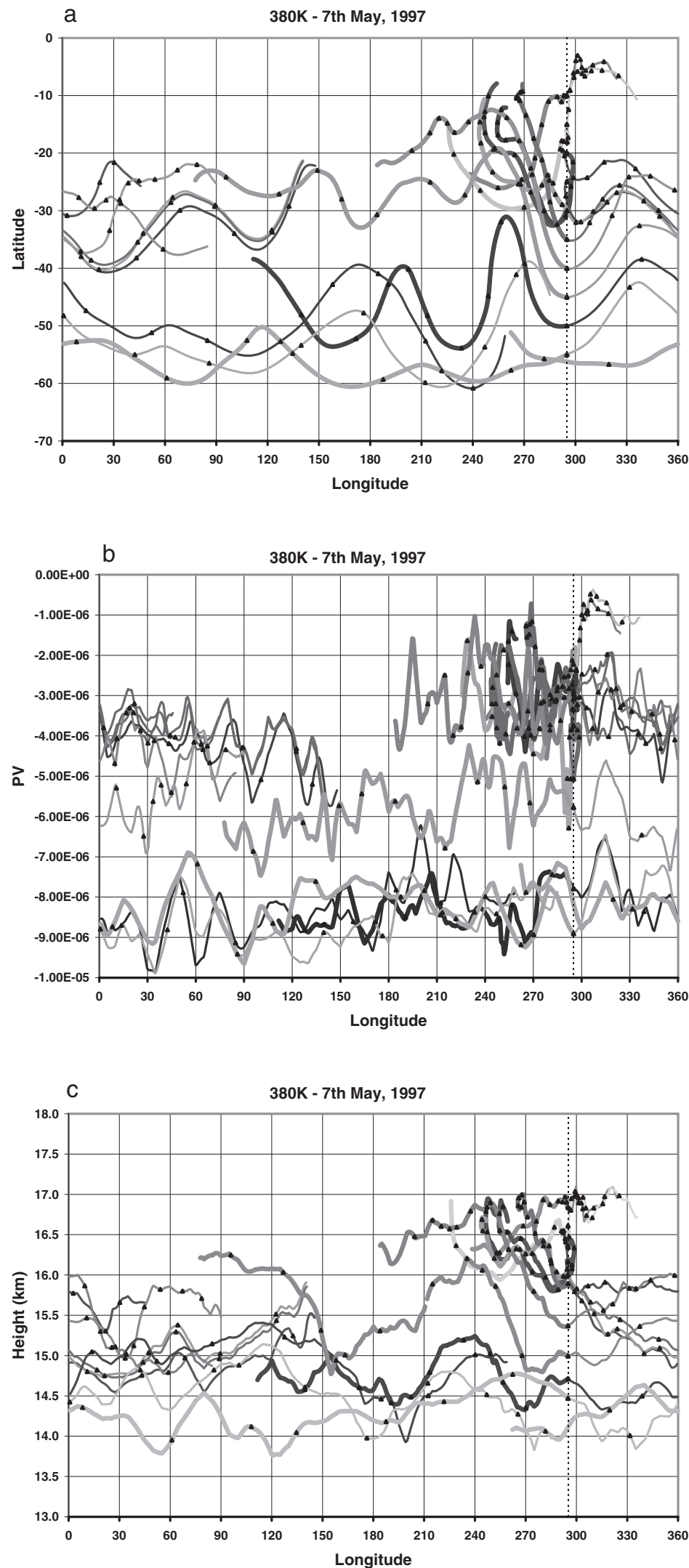

Figure 11. 10-day backward and forward trajectories centered about 7 May near the tropopause on the $380 \mathrm{~K}$ isentropic surface (a). The PV-longitude (b) and height-longitude (c) show parcel evolution along the trajectories. Trajectories were started every $5^{\circ}$, between 10 and $55^{\circ} \mathrm{S}$, along $65^{\circ} \mathrm{W}$. The vertical dashed line corresponds to the longitudinal axis from which all backward and forward trajectories originated. 

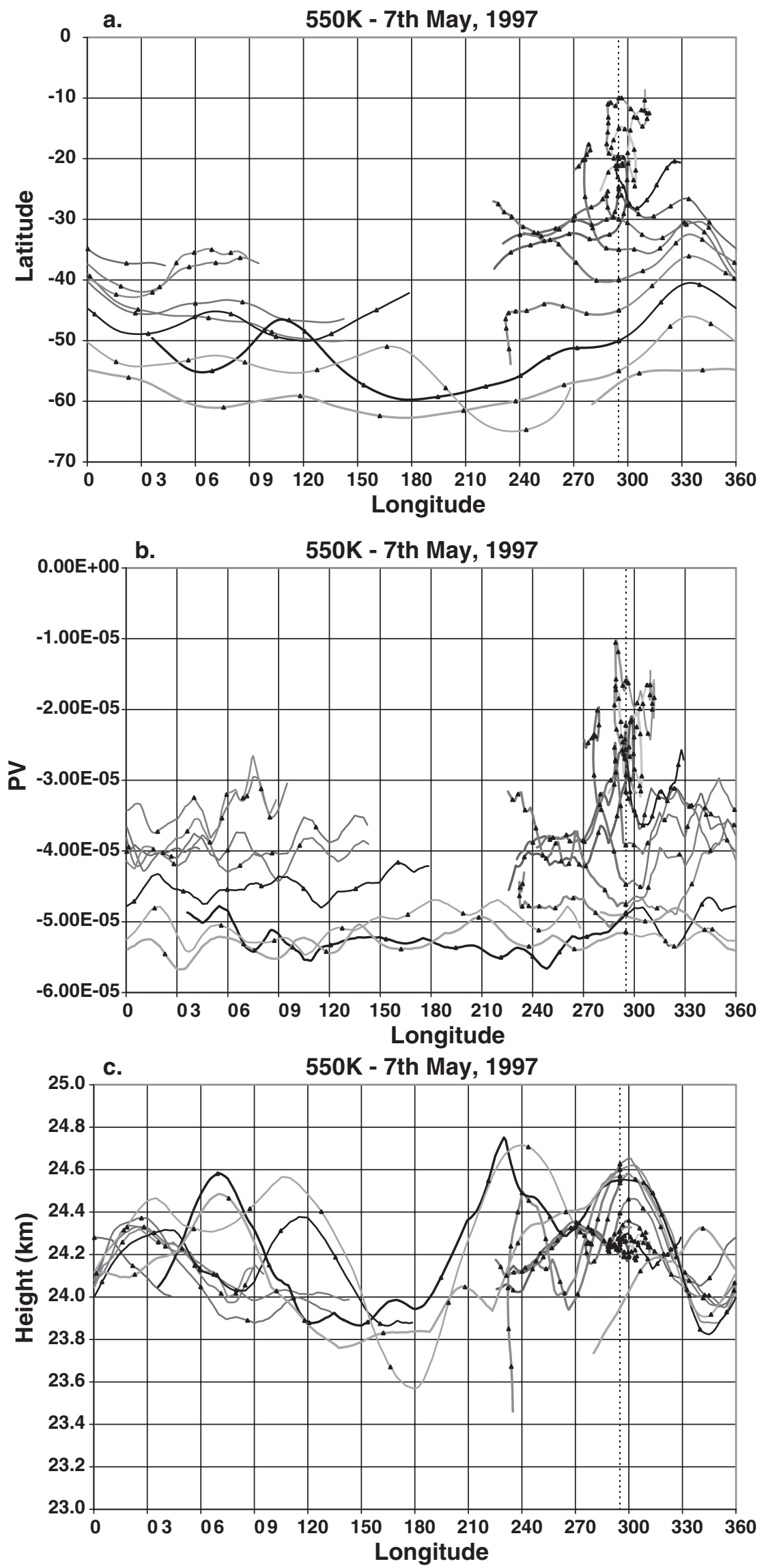

Figure 12. Same as Figure 11, centered about 7 May, for trajectories on the $550 \mathrm{~K}$ isentropic surface. 


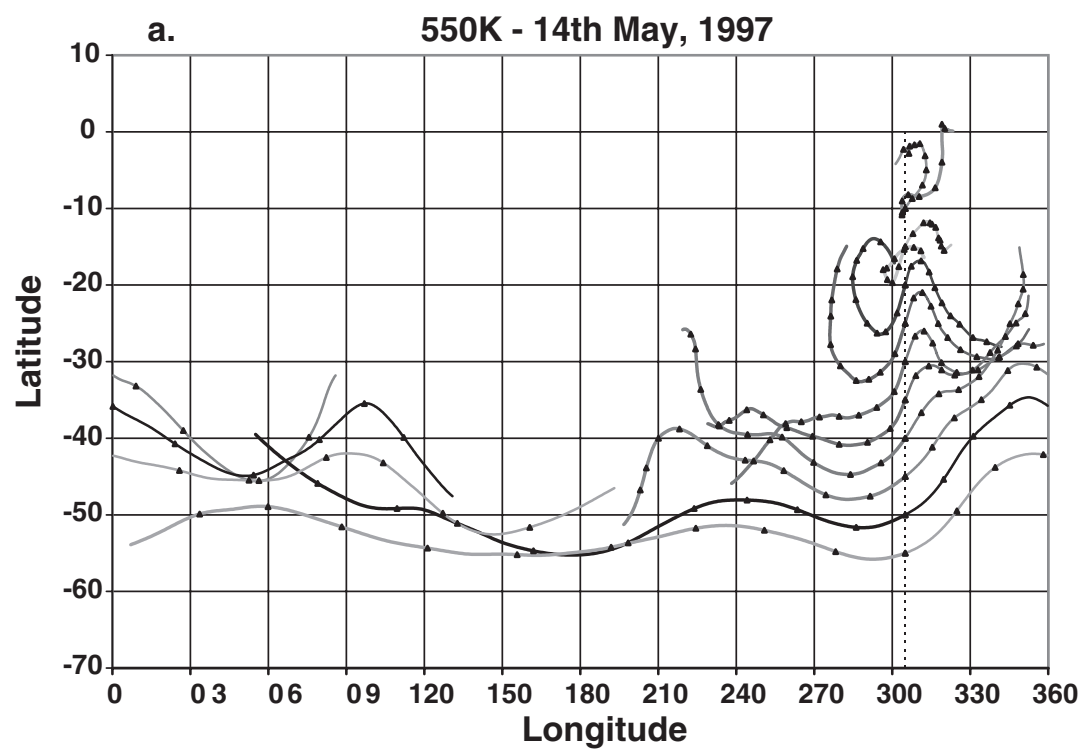

b.

550K - 14th May, 1997
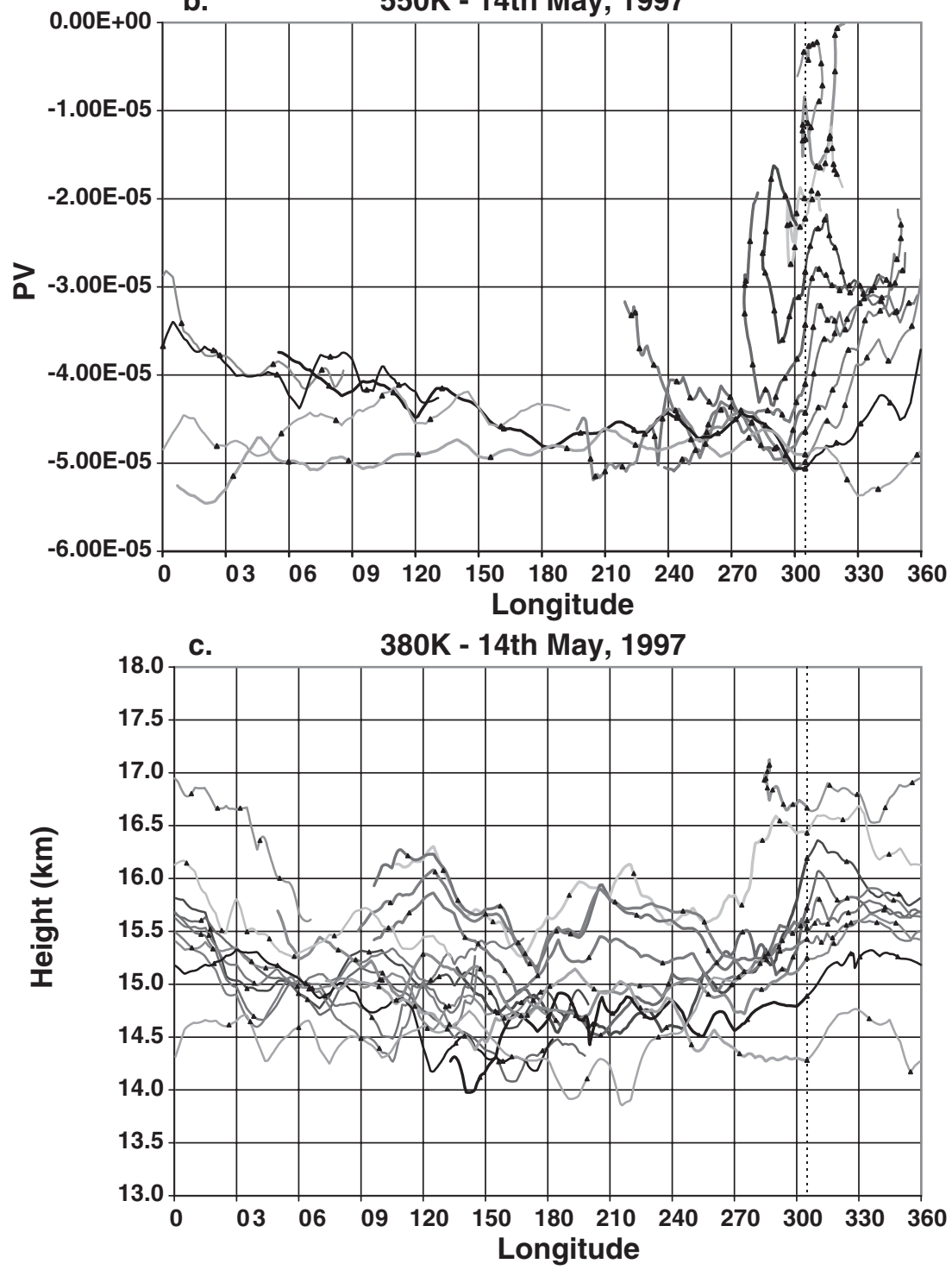

Figure 13. 10-day backward and forward trajectories centered about 14 May near the tropopause on the $380 \mathrm{~K}$ isentropic surface (a). The PV-longitude (b) and height-longitude (c) plots show parcel evolution along the trajectories. Trajectories were started every $5^{\circ}$, between 10 and $55^{\circ} \mathrm{S}$, along $55^{\circ} \mathrm{W}$. 
a

550K - 14th May, 1997

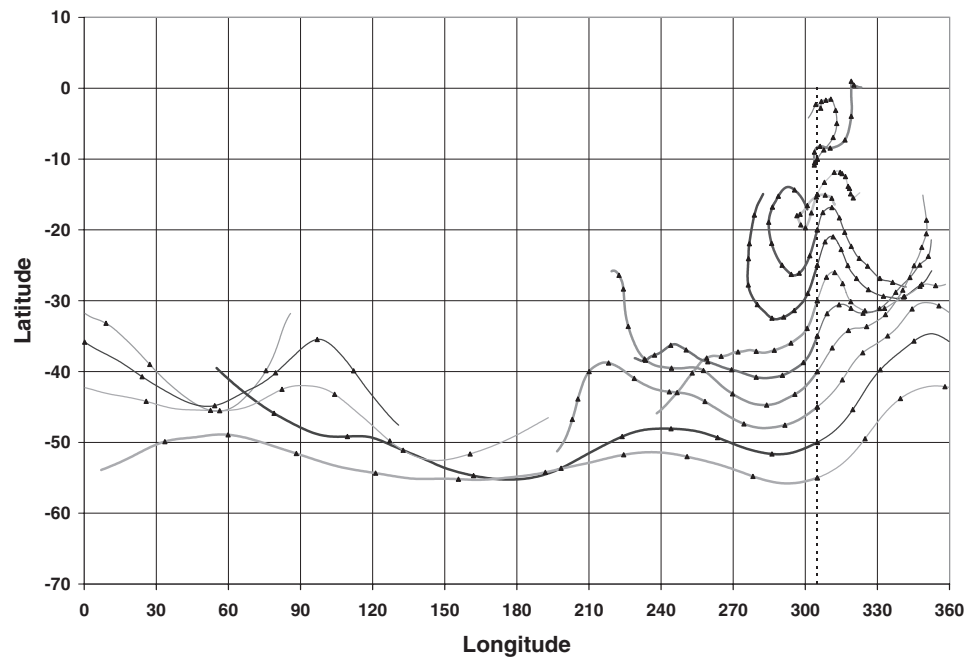

b

550K - 14th May, 1997

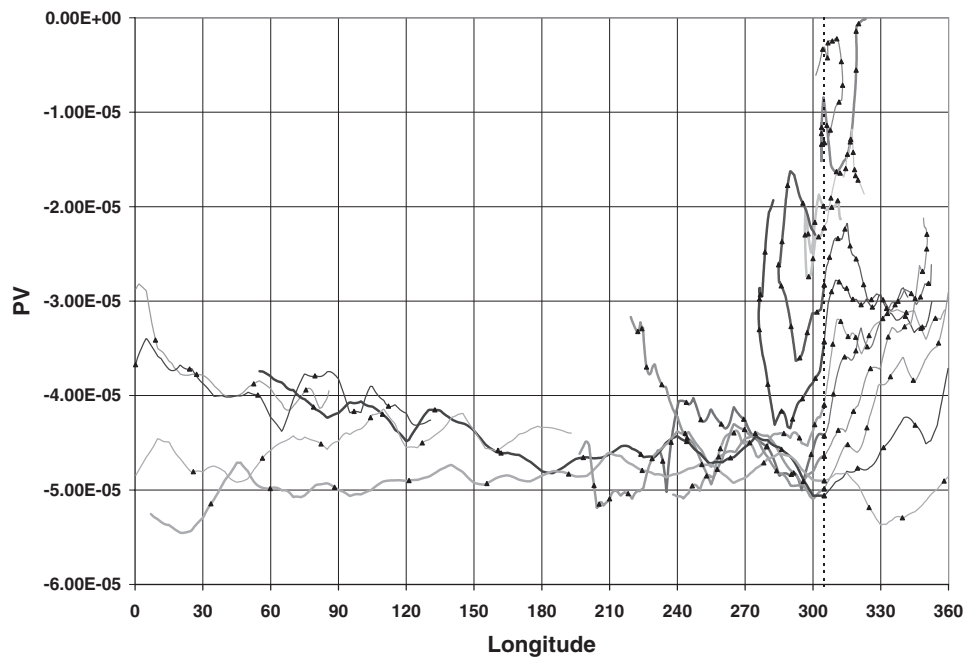

C

550K - 14th May, 1997

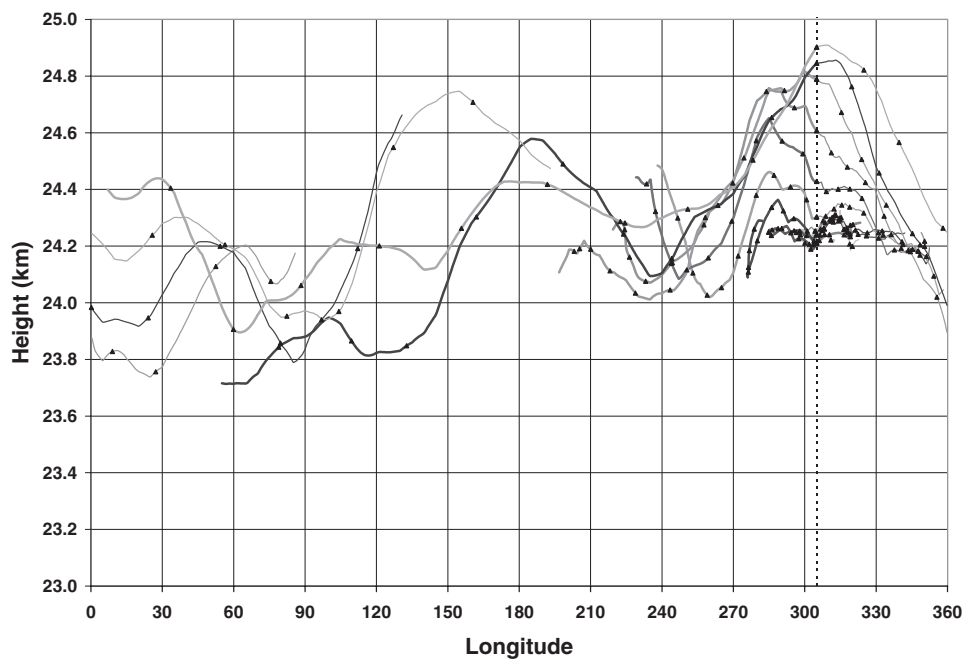

Figure 14. Same as Figure 13, centered about 14 May, for trajectories on the $550 \mathrm{~K}$ isentropic surface. 
in a couple days before 7 May. Strongly perturbed trajectories can also be seen between 35 and $15^{\circ} \mathrm{S}$. Parcels located between 10 and $30^{\circ} \mathrm{S}$ show significant meridional excursions for most days before 7 May, with very tight circulation about mean locations near that date. On the other hand south of $50^{\circ} \mathrm{S}$ the trajectories do have a fairly zonal displacement during the 20-day period under study. The parcels displaced from tropical and subtropical latitudes before 7 May did not return to lower latitudes in subsequent days.

[44] Inspection of the PV-longitude plot (Figure 11b) shows a clear division of the parcels into three groups, which in general conserve a mean PV value. The ones of tropical origin all have low PV values. Furthermore, the ones north of $20^{\circ} \mathrm{S}$, with sources closer to the Equator, appear to undergo the most significant PV changes, which could be due to the aforementioned quality problem in the trajectories equatorward of $20^{\circ}$. The parcel located at $35^{\circ} \mathrm{S}$ on 7 May appears as a class of its own, though equatorward parcels appear to drift to similar values in the southward motion, during the latter part of the sample. Parcels with trajectories at higher latitudes (light green and purple) maintain a more or less steady PV throughout the period.

[45] The height-longitude plot shows interesting features (c). As would be expected, during the southward displacements, parcels should move into lower heights. This indeed happens, except on the days before and after 7 May, for trajectories between 35 and $45^{\circ} \mathrm{S}$ (gray, orange and purple), i.e., where the minihole event was found. Despite the southward motion during 6 May the parcels maintain a constant height or actually rise, showing a vertical displacement of the isentropic layer in the region of high pressure. During the 7 th despite the northward motion of the parcels initially there is a decrease in height followed by a slow ascent.

[46] Above, at $550 \mathrm{~K}$ (Figure 12a), the trajectories were still perturbed by a meridional circulation, which is not as strong as at $380 \mathrm{~K}$, particularly at higher latitudes. The most significant meridional excursions can be seen north of $40^{\circ} \mathrm{S}$. The zonal and meridional displacement equatorward of $40^{\circ} \mathrm{S}$ are also observed but not as strong as at $380 \mathrm{~K}$. At lower latitudes the extent of the zonal displacement is also limited with respect to the $380 \mathrm{~K}$ layer, pointing to the existence of stronger zonal winds in the lower layer. The displacement poleward of $45^{\circ} \mathrm{S}$ is of the same order at both levels. The separation of the trajectories into PV clusters is not as distinct (Figure 12b), though the increase in PV as the parcel origin is located further south can be seen. As before the largest changes in PV are observed for the parcels closest to the Equator. Inspection of the height evolution (Figure 12c) shows that despite the reduced meridional parcel excursions there is an important and simultaneous vertical displacement, for the parcels found between 30 and $50^{\circ} \mathrm{S}$, on the days close to 7 May. There the vertical displacement is about 200-600 $\mathrm{m}$ before and after the passage over the minihole region, even more significant that at $380 \mathrm{~K}(250 \mathrm{~m})$. Such a behavior confirms the vertical extent of the perturbation.

[47] Poleward of $50^{\circ} \mathrm{S}$ the displacement of the air parcels at both levels is fairly consistent and thus the changes introduced in the total ozone column by differential displacement of the air parcels is limited. However, equator- ward of $50^{\circ} \mathrm{S}$ a significant shearing and stretching of the air column takes place as can be seen from the comparison of the trajectories at the two levels. As a matter of fact the change in the elements or shearing of the total ozone column is more significant between 40 and $25^{\circ} \mathrm{S}$ before 7 May. Afterward the parcels appear to move, at both levels, in a fairly orderly fashion between 30 and $40^{\circ} \mathrm{S}$.

[48] The trajectories calculated for the second ozone minihole episode (Figures 13 and 14) show a more organized behavior, particularly at mid to high latitudes and even more so at $550 \mathrm{~K}$. In this case the 20-day window is centered about 14 May, once the second blocking event is established and growing strong. On the $380 \mathrm{~K}$ surface (Figure 13a), the air parcels located between 30 and $50^{\circ} \mathrm{S}$ on that day came mostly from a far narrower latitude band, between approximately 22 and $35^{\circ} \mathrm{S}$, over the Indian Ocean and Western Australia. A highly ordered displacement occurred during the first week or so, i.e., between 4 and 10 May, after which the trajectories diverge while keeping approximate parallel paths. Some of the parcels (turquoise, purple and dark green) experience a southward excursion followed by a northern motion between 10 and 14 May, as if contouring a high pressure zone. The main flow of parcels took place along a strong UT/LS jet. The remaining parcels continue with their northwesterly motion and then diverge as they begin a northward motion on 14 May. This divergence coincides with the approach and crossing of the Andes, when the second minihole maximized. After the second blocking event peaks on 17 May these parcels continue to move in a more or less orderly fashion in a narrow latitude band about $5-10^{\circ} \mathrm{S}$ of their original latitude band. Poleward of $50^{\circ} \mathrm{S}$ there are strong meridional oscillations, which do not appear to be strongly related to the flow at midlatitudes except close to the center of the period under study. Equatorward of $30^{\circ} \mathrm{S}$ the trajectories closest to midlatitudes near the center of the period do show a limited influence of the blocking. The parcel at $10^{\circ} \mathrm{S}$ (on 14 May) is the only parcel of tropical origin this time.

[49] As would be expected from such a limited latitudinal origin, the parcels do not show such a clear PV clustering as a function of their origin (Figure 13b). Most have higher PV values than their counterparts on 7 May. On the other hand there is a height increase during the days before 14 May, despite the southward motion of the parcels (Figure 13c). The rise is about 300 to $600 \mathrm{~m}$. A much weaker height increase can be seen on subsequent days, though after the 17 th most parcels experience a descent along their southeastward motion.

[50] Inspection of the trajectories at $550 \mathrm{~K}$ (Figure 14a) yield a surprisingly orderly behavior of the air parcels for almost all the latitudes sampled. At mid to high latitudes the trajectories show minor departures from a zonal flow. The southernmost point is reached a couple of days before 14 May. The southwesterly flow after 14 May is particularly surprising since it points to broad latitudinal band subject to a fairly similar meridional flow perturbation even further north than at the $380 \mathrm{~K}$ surface. Such similar trajectories at the two levels imply that the shearing of the vertical ozone columns is somewhat more limited during this period. It must be noted that the similarities between the trajectories near the tropopause and the upper layer are rather surprising since, as pointed out above, the tropopause did not show 
such a strong signature of the blocking event as for the first blocking. Note the significant anticyclonic circulation between 20 and $30^{\circ} \mathrm{S}$ for all 10 days before 14 May.

[51] The trajectories can be separated into two PV clusters at this height (Figure 14b), one for the parcels of tropical origin and the other for the midlatitude ones. Interestingly enough some of the midlatitude parcels show a reduced PV conservation after 14 May. The parcel heights show a considerable rise $(200$ to $600 \mathrm{~m})$ at most latitudes for at least $3-5$ days (depending on latitude) before 14 May. This is significant considering the limited southward motion of the parcels at a time which, if anything would have implied a slight height decrease.

\section{Discussion}

[52] The above results show that the total ozone depressions or miniholes observed during May 1997, due to their evolution and spatial distribution, were due to the response of the ozone layer to major dynamic perturbations in the troposphere and lower stratosphere. It could be argued that chemical processes might have been involved in the genesis of these events. In particular this could be the case for the first event given the very low lower stratospheric temperature at the time. The Buenos Aires radiosonde data for 6 and 7 May show lower stratospheric temperatures between 195 and $200 \mathrm{~K}$. The Comodoro Rivadavia $\left(45.8^{\circ} \mathrm{S}\right)$ radiosonde data also show values just less than $200 \mathrm{~K}$. These temperatures are almost $10 \mathrm{~K}$ below the radiosonde climatology for these locations, at this time of the year. On the other hand, the temperatures observed during the second event were not as low, limiting the possibility of heterogeneous processes. The possible implications of such low temperatures for the ozone chemistry during the first minihole event are currently being evaluated. However, the evidence discussed below points essentially toward dynamic processes.

[53] It would appear that the main point in common for the mid to low latitudes minihole events are the apparent low ozone "seed areas" resulting from the wave 5 perturbation to the total ozone column as observed for 2 May. Indeed, the origin of these events can apparently be traced back to the two low ozone regions moving over the South Cone area during May 1997's first fortnight. According to Salby [1982] the wave 5 perturbation extends all the way down to at least $500-700 \mathrm{hPa}$. The evidence presented in the previous section shows that the evolution of these "seed areas" into deep depressions or even miniholes is linked to the development of blocking situations. It would be tempting to infer some link between the genesis of the blocking events and this planetary wave, which appears to advect these low ozone regions as it evolves. Furthermore the Andes mountain range could be interacting with the mean flow and the wave to trigger blocking events during such perturbed circulation [Berbery and Nuñez, 1989]. Indeed the Andes mountain range is known to have a significant interaction with the Southern Hemisphere general circulation and the weather on their lee side. The differences between our results and those obtained by Barsby and Diab [1995], for the southern region of Africa and surrounding oceans, could indeed be due to the effects of the Andes upon the strength and kind of weather systems prevailing this side of the Atlantic Ocean. However, it is not possible to further explore the possible relationships between the planetary wave and the genesis of the blocking events, within the scope of this work.

[54] Inspection of the back trajectories shows that the air parcels involved in the different layers of the total columns during the peak days of the events were not initially located in the "seed areas" associated with the wave 5 event. This is particularly so during the second event, where, at $380 \mathrm{~K}$, air parcels located within the ozone depression on 14 May were located, ten days before, over the Indian Ocean, Australia, New Zealand and the Central Pacific. At those locations the column ozone had either weak negative or positive anomalies. In other words none were located from the onset within the second low ozone region observed in the wave pattern. The same applies to the parcels at $550 \mathrm{~K}$. The midlatitude forward trajectories, at $380 \mathrm{~K}$, during the 10 next days, also pass through regions of positive and negative anomalies. These end, on 24 May, almost in the same region they were located 20 days before. The forward trajectories for the first event, beginning 7 May at $380 \mathrm{~K}$, do not show evidence of sustained low ozone values along their path, which would be expected had there been substantial chemical depletion in the lower stratosphere in the core of the first minihole event. As pointed out by Vaughan and Price [1991] the lower stratospheric air column stretches or becomes compressed, increasing or reducing the ozone column, as it moves over the various meteorological systems affecting the tropopause and the lower stratosphere. Such behavior points to the dynamic/synoptic nature of the process involved in the evolution of the miniholes, and discards a dominant role for chemical processing of ozone.

[55] A further characteristic of the first of these ozone depressions and the second stage of the second minihole is their position, as the blocking pattern develops, along the trailing edge of the ridges/leading edge of the troughs, close to their meridional (poleward) extreme and near the location of the steepest geopotential height gradient. During the development of the blocking situation, in particular the first one, the low ozone region can be observed to move toward the southern end of the event along the region of strongest shears. This implies that the depression evolves into a minihole near the region of greatest shear and hence vorticity anomaly. Similar behavior can also be observed in the maps for a North Atlantic blocking event presented by Vaughan and Price [1991]. The high ozone region following the second minihole event on the other hand appears almost over the axis of the trough, showing a different response for positive ozone anomalies. Thus the strength of the gradient appears to be significant in determining the depth of the ozone depression.

[56] The tropopause height appears as a determinant factor in the depth of the ozone depression or the peak values of the ozone ridge. Indeed during the second blocking the tropopause did not have major vertical displacements or sharp gradients in the region of the minihole. It would have been expected that this blocking, which extends almost into the middle stratosphere with a baroclinic signature, with orderly trajectories at different levels at least up to $50 \mathrm{hPa}$, and significant isentropic levels height increases throughout the lower stratosphere, could have resulted in significantly low ozone values. Yet this was not the case, as 
can be observed during the peak of the blocking event at the surface around 17 May. On the other hand during the first blocking, which was barotropic in nature, the tropopause experienced a major increase in height well into the middle latitudes, as well as cooling, and the very low ozone values reached are colocated close to the southern edge of this tropopause rise. The lowest ozone values were found where the tropopause pressure had a very significant gradient. Minimum column values did not necessarily occur at the location of the highest tropopause, equatorward of this region, but rather in the pressure gradient region. Similarly, the deep high-latitude minihole is also linked to a rise in the tropopause, associated with anticyclone activity. The high ozone anomaly that follows this event was very well colocated over the very low tropopause region that moved over the Southern Cone with the cold front that brought an end to the period of abnormally hot surface weather. Thus it appears that the absolute vertical displacement of the tropopause is not as significant as the relative change in height with respect to the average tropopause position.

[57] Inspection of the trajectories during the few days before the 12 May minimum, the second deepest at midlatitudes, show that the flow diverged at this time, reaching a maximum divergence that day. Given that the tropopause did not play a significant role, neither because of its height nor the shearing of its pressure field, this event appears to be the result mainly of the divergence of the flow over the isentropic surfaces.

[58] It should be borne in mind that, while the column ozone anomalies indeed point to a significant contribution from the tropopause displacements, the field deformations and even more so the trajectory analysis confirm the significant penetration of tropospheric synoptic scale systems into the lower stratosphere. In other words such tropospheric systems interact with the lower stratosphere not only through the fluctuations they impose upon the tropopause but also contribute to field perturbations on isentropic surfaces within this region.

\section{Summing Up}

[59] The above results show that during this short period the low ozone/minihole events that took place in the vicinity of the South Cone of South America were basically due to tropospheric dynamic processes that penetrate into the lower stratosphere. Each of these was the result of a different combination of such mechanisms. The first, extreme low ozone event, characterized by significant transport of air of subtropical to tropical origin, was mainly caused by a rather sharp and significant tropopause rise. The transport of low PV air, on the other hand, does not lead to major changes in the ozone content given that the ozone concentration does not change significantly within the latitudinal range of the transport. On the other hand, for the second event can be considered a two-stage process, with different mechanisms involved. At the beginning it was due to the horizontal advection and divergence of the flow, as it contoured the first blocking event. The largest ozone depression during this stage was reached on 12 May, with core values under 220 DU. This ozone-hole began to vanish as the second blocking event grew, but what appeared to be the remnants of the first stage or more likely a somewhat perturbed synoptic situation resulting in weak low ozone perturbations, developed into a new fairly significant low ozone region. It was not as strong as on 12 May, however. This is due to the fact that the tropopause was not much affected during this second stage, displaying a rather complex behavior. Thus this ozone depression did not develop into a minihole with characteristics similar to the first one. The high latitude, fast moving ozone hole, was strongly linked to the anticyclone below, in agreement with minihole descriptions at high northern latitudes. Of these dynamic mechanisms, the tropopause rise appears to be the determinant factor as to the depth of the ozone depression, though at times advection and divergence of the flow can be as significant.

[60] In other words during a period slightly longer than a fortnight, four important ozone anomalies, one of them the most important negative anomaly on record for the region, have different dynamic sources. The above results show that a careful analysis of the tropospheric and lower stratospheric synoptic situation is necessary for the typification of significant ozone anomaly events, considering that apparently similar perturbed weather surface conditions led to the formation of ozone depressions/miniholes with different genesis. Clearly the degree of interaction and amount of contribution of the two mechanisms proposed by Salby and Callaghan [1993] determine the evolution and strength of the process.

[61] Finally it must be noted that 1997 was an El Niño year and the circulation was highly perturbed. During La Niña years the circulation in the region is strongly zonal. Hence it is possible that events such as the ones described above occur mainly during strong El Niño years such as 1997.

[62] Acknowledgments. This work was possible thanks to grant IAIISP 3-076 from the Inter-American Institute for Climate Change Research and ANPCYT PICT-97 2197 and PICT-99 6588 from the Agencia Nacional Para la Promoción de la Ciencia y la Técnica (Argentina). The authors also wish to thank the Goddard Space Flight Center and Paul Newman for the use of the Goddard Automailer for the PV maps and the trajectory calculations and Lic. Gustavo Escobar (UBA) for preparing the basic meteorological information necessary for this work. The authors also wish to thank the reviewers for the comments and suggestions.

\section{References}

Barsby, J., and R. D. Diab, Total ozone and synoptic weather relationships over Southern Africa and surrounding oceans, J. Geophys. Res., 100, 3023-3032, 1995.

Berbery, E. H., and M. N. Núñez, An observational and numerical study of blocking episodes near South America, J. Clim., 2, 1352-1361, 1989.

Coughlan, M. J., A comparative climatology of blocking action in the two hemispheres, Aust. Meteorol. Mag., 31, 3-13, 1983.

Dobson, G. M. B., The laminated structure of the ozone in the atmosphere, Q. J. R. Meteorol. Soc., 99, 599-607, 1973.

Dobson, G. M. B., D. N. Harrison, and J. Lawrence, Measurements of the amount of ozone in the Earth's atmosphere and its relation to other geophysical conditions, part III, Proc. R. Soc. Lond., A112, 456-486, 1929.

Grandoso, H., and J. E. Nuñez, Análisis de una situación de bloqueo en la parte austral de América del Sur, Meteoros, 5, 35-54, 1955.

Hood, L., S. Rossi, and M. Beulen, Trends in lower stratospheric zonal winds, Rossby wave breaking behavior, and column ozone at northern midlatitudes, J. Geophys. Res., 104, 24,321-24,339, 1999.

James, P. M., A climatology of ozone mini-holes over the Northern Hemisphere, Int. J. Climatol., 18, 1287-1303, 1998.

Mc Cormack, J. P., and L. L. Hood, The frequency and size of ozone "minihole" events at northern midlatitudes in February, Geophys. Res. Lett., 24, 2647-2650, 1997.

Mc Kenna, D., R. L. Jones, J. Austin, E. V. Browell, M. P. Mc Cormick, A. J. Krueger, and A. F. Tuck, Diagnostic studies of the Antarctic Vortex during the 1987 Airborne Antarctic Ozone Experiment, J. Geophys. Res., 94, 11,641-11,668, 1989 . 
Orsolini, Y., D. Cariolle, and M. Deque, Ridge formation in the lower stratosphere and its influence on ozone transport: A general circulation model study during late January 1992, J. Geophys. Res., 100, 11,113$11,135,1995$.

Peters, D., and D. W. Waugh, Influence of barotropic shear on the poleward advection of upper-tropospheric air, J. Atmos. Sci., 53, 3013, 1997.

Rood, R. B., J. E. Nielsen, R. S. Stolarski, A. R. Douglass, J. A. Kaye, and D. J. Allen, Episodic total ozone minima and associated effects on heterogeneous chemistry and lower stratospheric transport, J. Geophys. Res., 97, 7979-7996, 1992.

Rutlland, J., and H. Fuenzalida, Bloqueo atmosférico en el cono sur de América conducente a un episodio de contaminación atmosférica en Santiago de Chile, in Proceedings of the 2nd Inter-American Congress and 5th Argentinean Meteorological Congress, pp. 6.2.1-6.2.6, Cent. Argent. de Meteorol., 1987.

Salby, M. L., A ubiquitous wavenumber-5 anomaly in the Southern Hemisphere during FGGE, Mon. Weather Rev., 110, 1712-1720, 1982.

Salby, M. L., and P. F. Callaghan, Fluctuations of total ozone and their relationship to stratospheric air motions, J. Geophys. Res., 98, $2715-$ 2727, 1993

Schoeberl, M. R., and A. J. Krueger, Medium scale disturbances in total ozone during Southern Hemisphere summer, Bull. Am. Meteorol. Soc., $65,1358-1365,1983$.

Schwerdtfeger, W., Bases para el pronóstico a medio plazo de las condiciones de temperatura en el otoño de Buenos Aires, Meteoros, 1, 33-45, 1951.

Sinclair, M. R., A climatology of anticyclones and blocking for the Southern Hemisphere, Mon. Weather Rev., 124, 245-263, 1996.
Solomon, S., Stratospheric ozone depletion: A review of concepts and history, Rev. Geophys., 37, 275-316, 1999.

Steinbrecht, W., H. Claude, U. Köhler, and K. P. Hoinka, Correlation between tropopause height and total ozone: Implications for log-term changes, J. Geophys. Res., 103, 19,183-19,192, 1998.

Taljaard, J. J., Synoptic meteorology of the Southern Hemisphere, Meteorology of the Southern Hemisphere, Meteorol. Monogr. No. 35, pp. $139-$ 211, Am. Meteorol. Soc., 1972.

Trenberth, K. E., and K. C. Mo, Blocking in the Southern Hemisphere, Mon. Weather Rev., 113, 3-21, 1985.

Van Loon, H., Blocking action in the Southern Hemisphere, Notos, 5, $171-$ $177,1956$.

Vaughan, G., and J. D. Price, On the relation between total ozone and meteorology, Q. J. R. Meteorol. Soc., 117, 1281-1289, 1991.

Vaughan, G., and C. Timmis, Transport of near tropopause air into the lower midlatitude stratosphere, Q. J. R. Meteorol. Soc., 124, 1559$1578,1998$.

S. A. Bischoff, P. O. Canziani, and R. H. Compagnucci, Grupo de Atmosfera Media, Departamento de Ciencias de la Atmósfera y los Océanos, Facultad de Ciencias Exactas y Naturales, Universidad de Buenos Aires/CONICET, Pabellon II, 2do Piso Ciudad Universitaria, 1428 Capital Federal, Buenos Aires, Argentina. (canziani@ic.fcen.uba.ar; pablo@auxiliadora.ic.fcen.uba.ar)

W. E. Legnani, Instituto de Cálculo, Facultad de Ciencias Exactas y Naturales, Universidad de Buenos Aires, Buenos Aires, Argentina. 